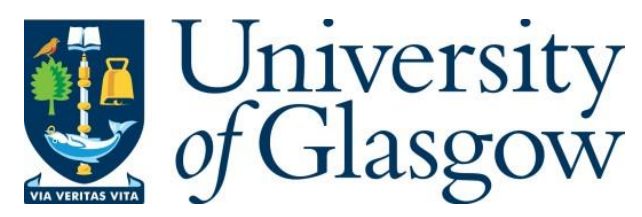

Aslam, M. et al. (2018) Anaerobic membrane bioreactors for biohydrogen production: recent developments, challenges and perspectives. Bioresource Technology, 269, pp. 452-464.

There may be differences between this version and the published version. You are advised to consult the publisher's version if you wish to cite from it.

http://eprints.gla.ac.uk/173342/

Deposited on: 12 December 2018

Enlighten - Research publications by members of the University of Glasgow http://eprints.gla.ac.uk 


\section{Anaerobic Membrane Bioreactors for Biohydrogen Production: Recent Developments, Challenges and Perspectives}

Muhammad Aslam, ${ }^{\mathrm{a}, \mathrm{b}}$, Rizwan Ahmad ${ }^{\mathrm{a}, \mathrm{b}, \mathrm{c}}$, Muhammad Yasin, ${ }^{\mathrm{a}, \mathrm{b}}$, Asim Laeeq Khan ${ }^{\mathrm{a}, \mathrm{b}}$, Muhammad Kashif Shahid $^{\mathrm{d}}$, Shakhawat Hossain ${ }^{\mathrm{e}}$, Zakir Khan ${ }^{\mathrm{a}}$, Farrukh Jamil ${ }^{\mathrm{a}}$, Sikander Rafiq ${ }^{\mathrm{a}}$, Muhammad Roil Bilad ${ }^{\mathrm{f}}$ Jeonghwan $\mathrm{Kim}^{\mathrm{c}}$, Gopalakrishnan Kumar ${ }^{\mathrm{g} *}$

a Department of Chemical Engineering, COMSATS University Islamabad (CUI), Lahore Campus, Defense Road, Off Raiwind Road, Lahore, Pakistan

${ }^{\mathrm{b}}$ Bioenergy \& Environmental Sustainable Membrane Technology (BEST) Research Group, COMSATS University Islamabad (CUI), Lahore Campus, Defense Road, Off Raiwind Road, Lahore, Pakistan

${ }^{c}$ Department of Environmental Engineering, Inha University, Namgu, 100 Inha-ro, Incheon, Republic of Korea

${ }^{\mathrm{d}}$ Department of Environmental \& Chemical Convergence Engineering, Daegu University, Daegudae-ro 201, Jillyang, Gyeongsan, Gyeongbuk, Republic of Korea

${ }^{\mathrm{e}}$ Department of Unmanned Vehicle Engineering, Sejong University, Seoul 143-747, Republic of Korea

${ }^{\mathrm{f}}$ Chemical Engineering Department, Universiti Teknologi PETRONAS, Bandar Seri Iskandar, 32610 Perak, Malaysia

${ }^{\mathrm{g}}$ School of chemistry, Bioscience and Environmental Engineering, University of Stavanger, Norway

*Corresponding author

Email address: gopalakrishnanchml@gmail.com (G. Kumar) 


\begin{abstract}
Biohydrogen as one of the most appealing energy vector for the future represents attractive avenue in alternative energy research. Recently, variety of biohydrogen production pathways has been suggested to improve the key features of the process. Nevertheless, researches are still needed to overcome remaining barriers to practical application such as low yields and production rates. Considering practicality aspects, this review emphasized on anaerobic membrane bioreactors (AnMBRs) for biological hydrogen production. Recent advances and emerging issues associated with biohydrogen generation in AnMBR technology are critically discussed. Several techniques are highlighted that are aimed at overcoming these barriers. Moreover, environmental and economical potentials along with future research perspectives are also addressed to drive biohydrogen technology towards practicality and economical-feasibility.
\end{abstract}

Keywords: Biohydrogen, Anaerobic membrane bioreactor, Fouling, Fermentation, reactor design 


\section{Introduction}

Recent concerns over climate change and depleting fossil fuels are driving to develop alternative biofuels as replacements for non-renewable fossil fuels. The challenges of dwindling fossil fuel reserves and anthropogenic climate change are driving intense research into sustainable energy resources (Bharathiraja et al., 2016; Chawla et al., 2018; Hallenbeck, 2009). Among the various biofuels options, biohydrogen is an attractive future energy carrier due to its potentially higher efficiency of conversion to usable power, high energy density and low generation of pollutants (Gassanova et al., 2006; Ghauri et al., 2011; Hallenbeck \& Ghosh, 2009; Nikolaidis \& Poullikkas, 2017; Winter, 2009). Recently, variety of technologies for hydrogen production from variable sources has been extensively investigated. Among those, hydrogen production from biomass represents one of the highly attractive options for being a less energy intensive and more economical process (da Silva Veras et al., 2017; Kataoka et al., 1997). Biohydrogen can be produced by several biological ways including photodecomposition of organic compounds by photosynthetic bacteria (photofermentation), biophotolysis of water using algae and cyanobacteria; and fermentative hydrogen production from organic waste streams (Hallenbeck \& Benemann, 2002; Show et al., 2011; Show et al., 2012). However, incomplete substrate conversion and the consequent low yields and generation rates have been major barriers to the practical application of biohydrogen technologies.

In recent years, several approaches have been proposed to surpass these drawbacks, such as the construction of more efficient and robust hydrogen producer microorganisms, fermentation optimization and bioreactor design (Boodhun et al., 2017; Guo et al., 2010; Jung et al., 2011). Fermentative bacteria can produce hydrogen gas continuously without any light source in anaerobic wastewater treatment (Kumar et al., 2017; Tao et al., 2007). In addition to 
hydrogen, such bacteria can produce other products to satisfy their metabolic needs and to further growth, these include organic acids, alcohol and acetone that can be converted into electricity sources, biodegradable plastics and fibers (Hallenbeck, 2005; Khan et al., 2016). Therefore, dark fermentation seems more feasible and there is remarkable progress ongoing toward practicality (Das \& Veziroglu, 2008; Hawkes et al., 2007; Kraemer \& Bagley, 2007). Conventionally, continuous stirred tank reactors (CSTRs) have been widely used for biohydrogen production by fermentative bacteria (Bartacek et al., 2007; Davila-Vazquez et al., 2008). CSTRs offer simple construction, ease of operation, effective homogeneous mixing and operation under variable conditions of substrate, $\mathrm{pH}$ and hydraulic retention time (HRT) (Kapdan \& Kargi, 2006; Wang \& Wan, 2009). However, potential risk of biomass washout has driven investigation and trails of several modified configurations of fermentation systems.

Among bioreactor designs, combining hydrogen fermenters with membrane technology (AnMBR) is one of the most promising solutions. Membranes in AnMBR, compared with CSTR, can prevent biomass loss from the reactor, thus permitting the long solid retention time (SRT) required for efficient treatment while allowing relatively short HRT (Aslam et al., 2014; Charfi et al., 2017b; He et al., 2012; Trad et al., 2015a). In addition, AnMBR produce high quality effluent, reduce plant footprint and produce flexibility in operation (Smith et al., 2014; Stuckey, 2012). Consequently, application of AnMBR has brought significant improvement in biohydrogen production efficiency in dark fermentation processes (Bakonyi et al., 2017; Bakonyi et al., 2014; Lee et al., 2009b; Lee et al., 2007; Noblecourt et al., 2017; Saleem et al., 2018; Singhania et al., 2012; Trad et al., 2015a). However, membrane fouling is still the main barrier in AnMBR applications (Aslam et al., 2017b; Aslam et al., 2015; Meng et al., 2017; Spagni et al., 2010). To date, several review papers have been published on membrane fouling and biogas 
production in AnMBRs (Lin et al., 2013; Ozgun et al., 2013; Shin \& Bae, 2018; Smith et al., 2012; Stuckey, 2012; Szentgyörgyi \& Bélafi-Bakó, 2010). The potentials of AnMBRs for biohydrogen production were not enlightened. Bakonyi et al. (2014) only reviewed biohydrogen related work done on membrane bioreactors in comparison with conventional CSTR counterparts. The research work related to potential of biohydrogen production with AnMBR technology has only simply or partially articulated. Recent studies have already proven technical feasibility of AnMBR for biohydrogen extraction from wastewater and other waste streams. Therefore, technical and economic feasibility study of AnMBR is a promising aspect. Hence, a critical review on recent technical innovations and emerging techniques to improve biohydrogen production is of crucial importance particularly in AnMBRs.

The present review enlightens promising prospect of AnMBRs for biohydrogen production by reviewing extensive research in the past two decades. This paper deals with recent advances and emerging issues in biohydrogen production with AnMBR technology. A more thorough discussion is carried out with respect to factors affecting biohydrogen production and techniques to improve its yields and generation rates. Finally, environmental and economic potentials are presented along with future research trends in AnMBR technology for biohydrogen production.

\section{Basic biohydrogen production technologies and their shortcomings}

Biohydrogen can be generated by several biological ways and classified into two major categories: light-dependent and dark fermentative processes. Major light independent process is dark fermentation, whereas light-dependent processes include photofermentation and photolysis. All biohydrogen production pathways depend on either a nitrogenase or hydrogenase for hydrogen evolution. These technologies derive energy either directly from light energy or 
indirectly via consuming photosynthetically derived carbon compounds. Among these, dark fermentation receives high scientific attention and pilot plants have recently been established (Khan et al., 2010; La Licata et al., 2011; Lin et al., 2011). Although fermentative hydrogen production is undoubtedly promising, intense research is need to overcome serious technical barriers before it become practical, preferentially by using wastewater and other waste materials (Akinbomi et al., 2015; Lee et al., 2010b; Sinha \& Pandey, 2011).

\subsection{Direct biophotolysis}

In this process, biohydrogen can be produced through the photosynthetic capability of an organism, for example a green algae or cyanobacterium, that uses captured solar energy to drive water splitting process (producing $\mathrm{O}_{2}$ ) and reduce ferredoxin - an electron carrier in the chloroplasts. Consequently, electrons are transferred to hydrogenases and/or nitrogenases enzymes (Fig.1a). Microorganisms release the excess electrons using hydrogenase enzyme under anaerobic or excessive energy conditions, which converts the hydrogen ions to hydrogen gas (Turner et al., 2008). Molecular hydrogen generation occurs, by recombining the electrons and protons extracted from the water splitting reactions, using chloroplast hydrogenase (Hankamer et al., 2007). Photolysis uses water as substrate which is abundant and generates simple products of $\mathrm{H}_{2}$ and $\mathrm{CO}_{2}$, as a result it demonstrates promising future prospect. However, there are technical barriers that need to be overcome. Current challenges, such as low light conversion efficiencies, oxygen-sensitive hydrogenase and requirement of expensive hydrogen impermeable photobioreactors; need to be addressed (Hallenbeck \& Ghosh, 2009). In addition, Kapdan and Kargi (2006) reported that hydrogen production can be suppressed by generation of oxygen during water splitting process. Major issues with the coproduction of hydrogen and oxygen include co-culture balance, photosynthetic and respiration capacity ratio, concentration and 
processing of cell biomass (Holladay et al., 2009). Under certain conditions, some microorganisms like algae can directly produce hydrogen. For example, Laurinavichene et al. (2008) revealed that sulfur-deficient green algae whose energy was gained from light under anaerobic conditions could induce the hydrogenase reactions to produce biohydrogen photosynthetically. The algae consume large amounts of cellular starch and protein; and these catabolic reactions help to sustain indirectly the hydrogen production process (Show et al., 2011).

\subsection{Photofermentation}

An anaerobic photosynthesis is carried out by a non-sulfur purple photosynthetic bacterium, which utilize captured solar energy to produce adenosine triphosphate (ATP) and high energy electrons through reverse electron flow that reduce ferredoxin. Proton reduction to hydrogen by nitrogenase is driven through ATP and reduced ferredoxin (See Fig. 1b). Unlike cyanobacteria and/or green algae in photolysis process, photosynthetic purple bacteria cannot derive electrons from water and therefore use organic compounds, usually organic acids or even dihydrogensulfide, as electron donor under anaerobic conditions (Hallenbeck \& Ghosh, 2009). This process can be promising in terms of complete conversion of substrate to $\mathrm{H}_{2}$ and $\mathrm{CO}_{2}$, and types of feed to the microbes (Hallenbeck \& Ghosh, 2009). However, researchers need to spend additional efforts to overcome high energy demand by nitrogenase, low light conversion efficiencies and expensive hydrogen impermeable photobioreactors.

\subsection{Dark fermentation}

Various organic substrates and wastewaters can be used as electron donors to produce biohydrogen at higher rates and lower cost in dark fermentation as compare to other biological pathways. Carbohydrate-rich substrates can be broken down to hydrogen and other products such 
as acids (lactic, acetic, butyric, etc.) and alcohols (ethanol, butanol, etc.) anaerobically using a variety of different microbes. The oxidation state of substrate, microbial distributions and environmental conditions such as $\mathrm{pH}$ and hydrogen partial pressure can affect product distribution in this process (Hallenbeck \& Ghosh, 2009; Kapdan \& Kargi, 2006). Dark fermentation under anaerobic conditions seems to be most favorable among the bioproduction processes because there is no need of direct solar input and variety of waste streams can be treated for hydrogen production. For glucose degradation to pyruvate, glycolytic pathway is the most common path (Fig.1c) found in all major microorganisms and functions (Prescott et al., 2002). In this route, glucose is converted into pyruvate associated with conversion of NAD+ to NADH (nicotinamide adenine dinucleotide) through anaerobic glycolysis (Eq. (1)). NADH, acetyl-CoA levels and environmental conditions may affect the disposal of electrons through pyruvate-ferredoxin oxidoreductase or NADH-ferredoxin oxidoreductase and hydrogenase. Therefore, NADH consumption to generate some reduced compounds (such as lactate, ethanol and butanol) has to be utilized to balance the oxidation-reduction state, resulting in a lower yield of biohydrogen (Show et al., 2011).

$$
\mathrm{C}_{6} \mathrm{H}_{12} \mathrm{O}_{6}+2 \mathrm{NAD}^{+} \rightarrow 2 \mathrm{CH}_{3} \mathrm{COCOOH}+2 \mathrm{NADH}+2 \mathrm{H}^{+}
$$

Two routes can be found to form molecular hydrogen in the presence of specific coenzymes, for example either by the re-oxidation of $\mathrm{NADH}$ path or by formic acid decomposition route which could be represented by Eqs. (2) and (3):

$$
\begin{aligned}
& N A D H+H^{+}+2 F^{2+} \rightarrow 2 H^{+}+N A D^{+}+2 F d^{+} \\
& 2 F^{+}+2 H^{+} \rightarrow 2 F d^{2+}+H_{2}
\end{aligned}
$$




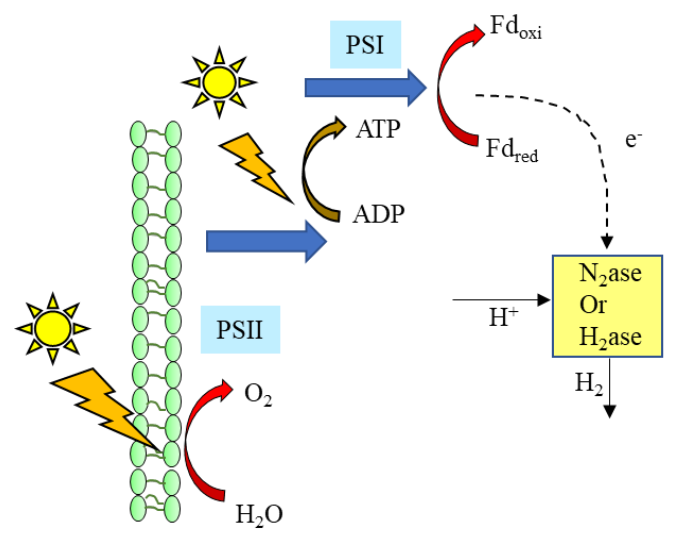

(a)

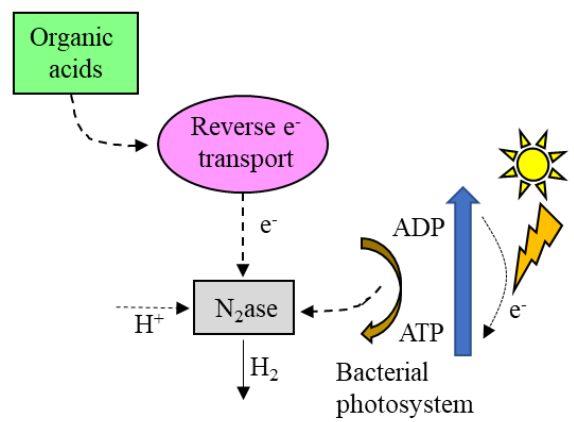

(b)

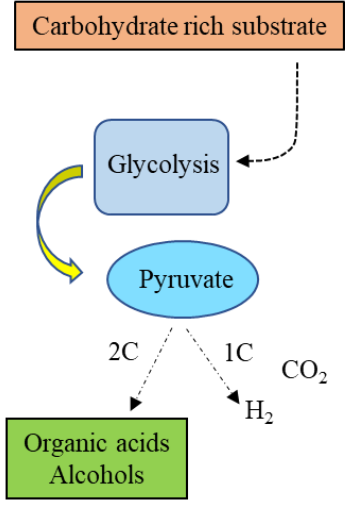

(c)

Fig. 1. Conceptual illustration of basic biohydrogen production technologies (a) biophotolysis, (b) photofermentation, (c) dark fermentation

\section{Technical overview of anaerobic membrane bioreactors}

AnMBR technology is a promising way for wastewater and waste management, pollution control in environment and energy sustainability due to its smaller foot print required while producing higher effluent (permeate) qualities than conventional treatment processes. It is an integrated system where membrane module is coupled with an anaerobic bioreactor (Aslam \& Kim, 2017; Charfi et al., 2018b; Khan et al., 2016). Membranes separate liquid from biomass and can retain biomass effectively in the bioreactor, thus permitting the long SRT required for efficient treatment while allowing operation at the short HRT needed for cost effectiveness (Aslam et al., 2018b). It also offers potential benefits for the bioprocesses where product formation separation is desired simultaneously in a compact system (Shin \& Bae, 2018). Regardless of the applications, AnMBR configurations can be categorized as: submerged/immersed and external/side stream (Fig. 2a and b). In the former case, membranes are submerged in the liquid phase of biological reactor or sometime immersed in a separate reactor. In side stream configuration, liquid filtration membrane is linked to the reactor from 
outside in a separate unit requiring an intermediate pumping step. Each scheme has positive and negative aspects and, the achievable value of trans-membrane pressure (TMP) is different and direction of flow is reverted. Higher TMP in side stream arrangement lead to decrease the exchange area needed for a give permeate flux and increase the demand of operation energy. On the other hand, the cleaning and replacement of membranes is easily in this configuration. Although, submerged AnMBRs are less energy intensive but larger membrane surface area are required to cope high permeate fluxes (Aslam et al., 2017b; Bakonyi et al., 2014; Khan et al., 2016; Singhania et al., 2012).

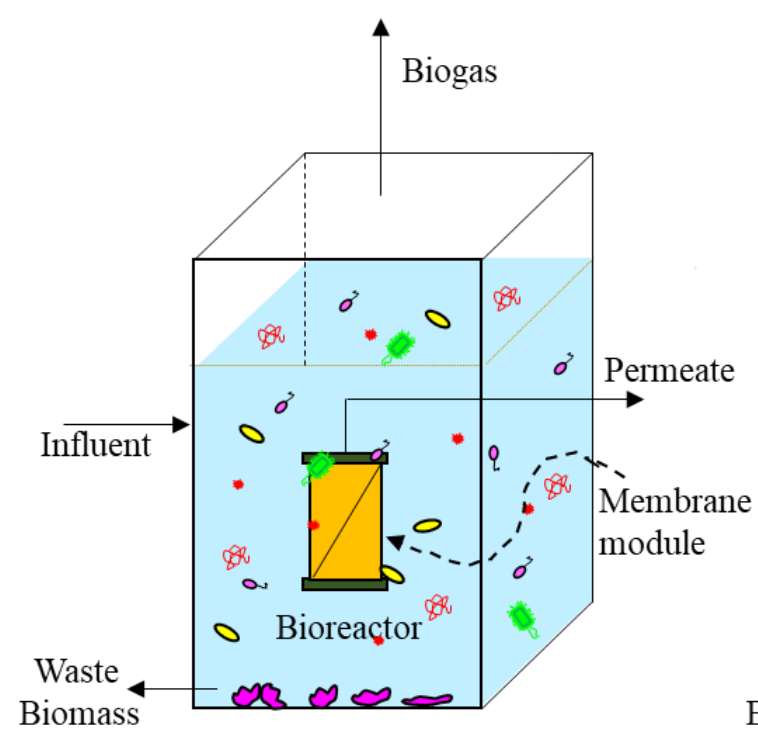

(a)

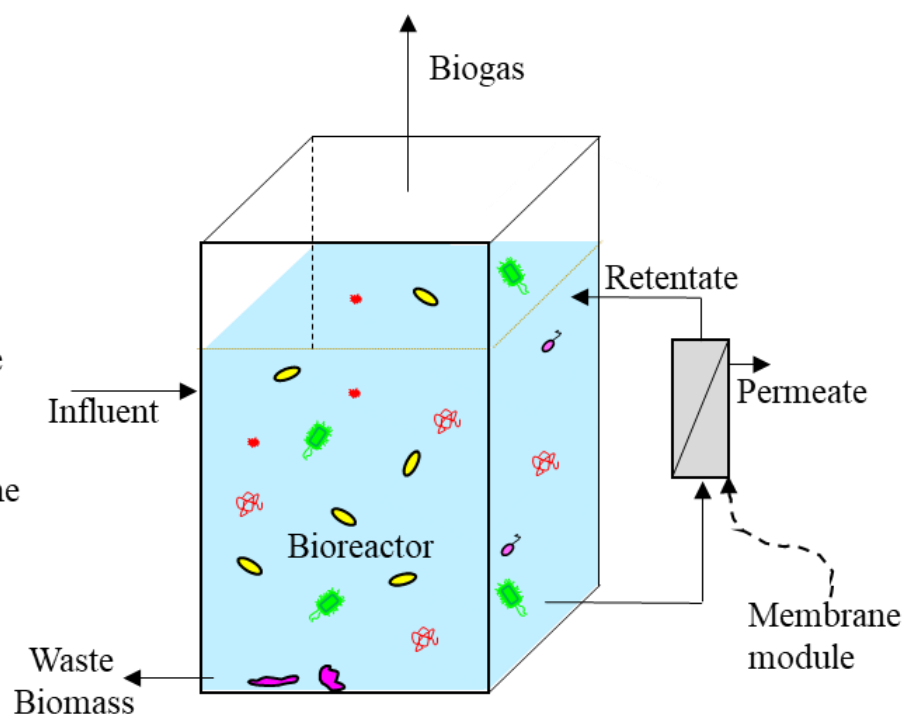

(b)

Fig. 2. Schematic diagram of AnMBR configurations (a) submerged, (b) external (side stream)

\subsection{Challenges and opportunities}

\subsubsection{Membrane fouling and energy demands}

Membrane fouling caused by deposition of foulants materials on membrane surface and/or within pore matrix is a long-standing challenge in AnMBRs because it deteriorates membrane permeability, thus demanding frequent chemical cleaning which can shorten membrane life time (Ahmad et al., 2016; Aslam et al., 2018a). Membrane fouling can be caused 
by a variety of different foulants such as particulates, organics, colloidal, microbes and microbial by-products, inorganics and combination thereof (Charfi et al., 2017b). Fig. 3 reveals the phenomenon of cake layer and TMP development in AnMBRs. To date, several review papers on membrane fouling focusing on the fouling reasons and available strategies (Fig.4) to cope this phenomenon have been published (Aslam et al., 2017b; Deng et al., 2016; Drews, 2010; Iorhemen et al., 2017; Le-Clech et al., 2006; Meng et al., 2017; Wang et al., 2014). Fouling inherently affects the process economy (increases the capital/operational cost) and should be restricted as much as possible. The fouling is inevitable phenomenon and could be controlled if mechanism and responsible substances are known. Membrane fouling is dependent on different factors (Fig. 4) related to operating conditions (operational flux, temperature, HRT, SRT, pH, hydrodynamics such as shear rate on the membrane surface), membrane characteristics (hydrophilicity/hydrophobicity, membrane pore size, roughness, surface charge, material and composition, porosity etc.) and bacterial/mixed liquor characteristics (SMP/EPS, hydrophobicity, ionic strength, charge, populations density, specie, growth phase and biological responses etc.) (Aslam et al., 2018a; Liao et al., 2006; Ozgun et al., 2013; Shahid et al., 2018; Singhania et al., 2012; Szentgyörgyi \& Bélafi-Bakó, 2010).

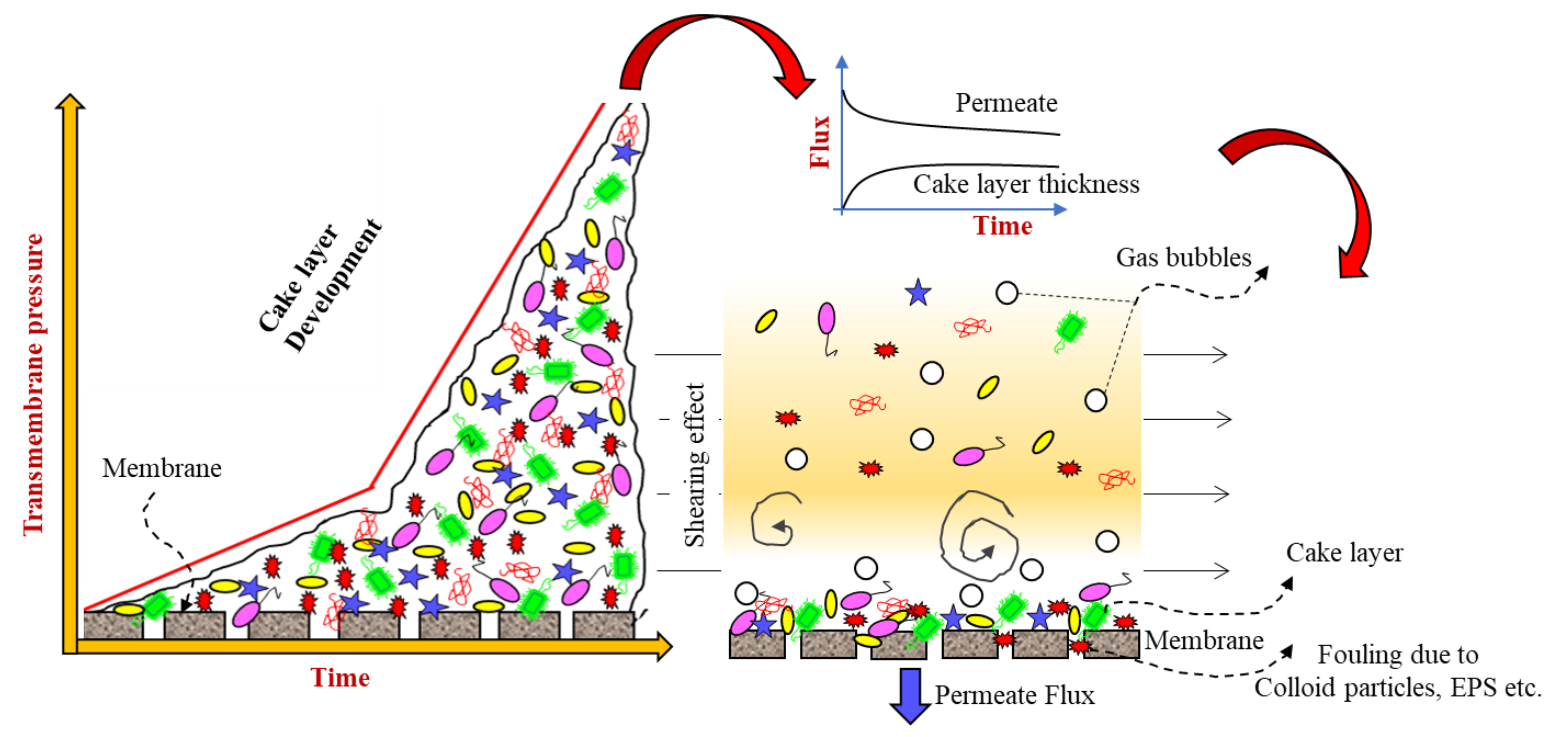


Fig. 3. Cake layer and corresponding TMP development phenomenon with time in anaerobic membrane bioreactors

Membrane fouling is a complex phenomenon and conventional strategies to mitigate fouling such as relaxation, backwashing, intermittent filtration cycles, addition of coagulants and adjusting membrane operational conditions such as cross-flow velocity, set-point flux, or any pretreatment technologies may not enough to cope with it. Recently, vibration through ultrasonic irradiation receives noticeable research interest. In addition, troubleshooting of fouling and scaling demands some other methods to recover membrane performance such as addition of chemicals such as sodium hypochlorite $(\mathrm{NaClO})$, sodium hydroxide $(\mathrm{NaOH})$, acids (for example citric acid, nitric acid, hydrochloric acid) and other agents such as ethylene diamine tetra acetic acid (EDTA) or ozone or $\mathrm{CO}_{2}$ purging (Meng et al., 2017; Shahid \& Choi, 2018; Wang et al., 2014). Although chemical cleaning is effective to combat membrane fouling, membrane can be damaged by frequent chemical treatment and shorten the life time of membranes. Polymeric membranes have been widely used in AnMBRs and are not stable against chemicals when recovery/maintenance cleaning is performed with strong oxidants such as chlorine. In addition, surface treatment of membranes can prevent undesired adhesive interactions between membrane and foulants materials by modifying membrane properties using additives or antimicrobial agents. Recently, there are upsurge of interests in applying ceramic and conductive membranes in AnMBRs due to low fouling tendency, great structural integrity and strong chemical resistant compared to polymeric membranes (Meng et al., 2017; Wang et al., 2014). Moreover, dynamic membrane has recently been proposed and cost effective alternative to conventional membranes because cheap underlying support (filter cloth and mesh) can be used to develop dynamic membrane. It can exploit the foulants deposits on a support medium for solid-liquid separation in AnMBR for biological hydrogen production. (Park et al., 2017; Saleem et al., 2018). 
Biogas sparging along the membrane surface has been widely applied to mitigate fouling in AnMBR systems. However, the energy requirement for biogas sparging often ranges from 0.7 to $3.4 \mathrm{kWh} / \mathrm{m}^{3}$, which is even higher than the energy required operating aerobic MBR system $\left(0.5-1.0 \mathrm{kWh} / \mathrm{m}^{3}\right)$. In recent years, combining biogas sparging with suspended carriers is considered as effective approach to mitigate membrane fouling at reduced gas sparging rates (Aslam et al., 2017a; Iorhemen et al., 2017). Nevertheless, biogas sparging still required much energy accounting for up to about $50-70 \%$ of the total energy consumed in AnMBR system (Aslam et al., 2017b). Thus, higher energy requirements for biogas sparging may diminish the potential advantages of AnMBRs.

New concept has been demonstrated by combining anaerobic fluidized bed bioreactor with submerged membranes (AFMBR). Here, granular activated carbon (GAC) particles are fluidized by recirculating bulk solution through it without any biogas sparging. GAC particles can provide not only mechanical cleaning to mitigate fouling on membrane but also high specific surface area for biofilm formation (Charfi et al., 2018a; Charfi et al., 2017a; Kim et al., 2011a). Recent studies reported that the electrical energy required to fluidize the GAC particles was less than $0.1 \mathrm{kWh} / \mathrm{m}^{3}$, which was significantly lower than required for biogas sparging in AnMBRs (Aslam et al., 2017c; Aslam et al., 2018b; Kim et al., 2011a). In addition, biological anti-biofouling strategies, target the sources which can initiate or accelerate it, include energy uncoupling, enzymatic disruption, use of microbial predation and bacteriophages, cell-wall hydrolysis and quorum quenching (Aslam et al., 2018a). Recent studies demonstrated that quorum quenching is one of the innovative ways to mitigate biofouling by disrupting signal molecules produced by the microorganisms for their communications (Aslam et al., 2018a; Oh \& Lee, 2018). Lee et al. (2016) attempted to bring pilot-scale with quorum quenching approach for 
fouling reduction. It was reported that TMP rise was delayed by $70 \%$ in comparison with conventional MBR without it. In addition, energy consumption was reduced to $0.2 \mathrm{kWh} / \mathrm{m}^{3}$, which was about $60 \%$ lower than conventional MBR system $\left(0.46 \mathrm{kWh} / \mathrm{m}^{3}\right)$. Nevertheless, integrated fouling control strategies may provide feasible solution at the aim to overcome this barrier.
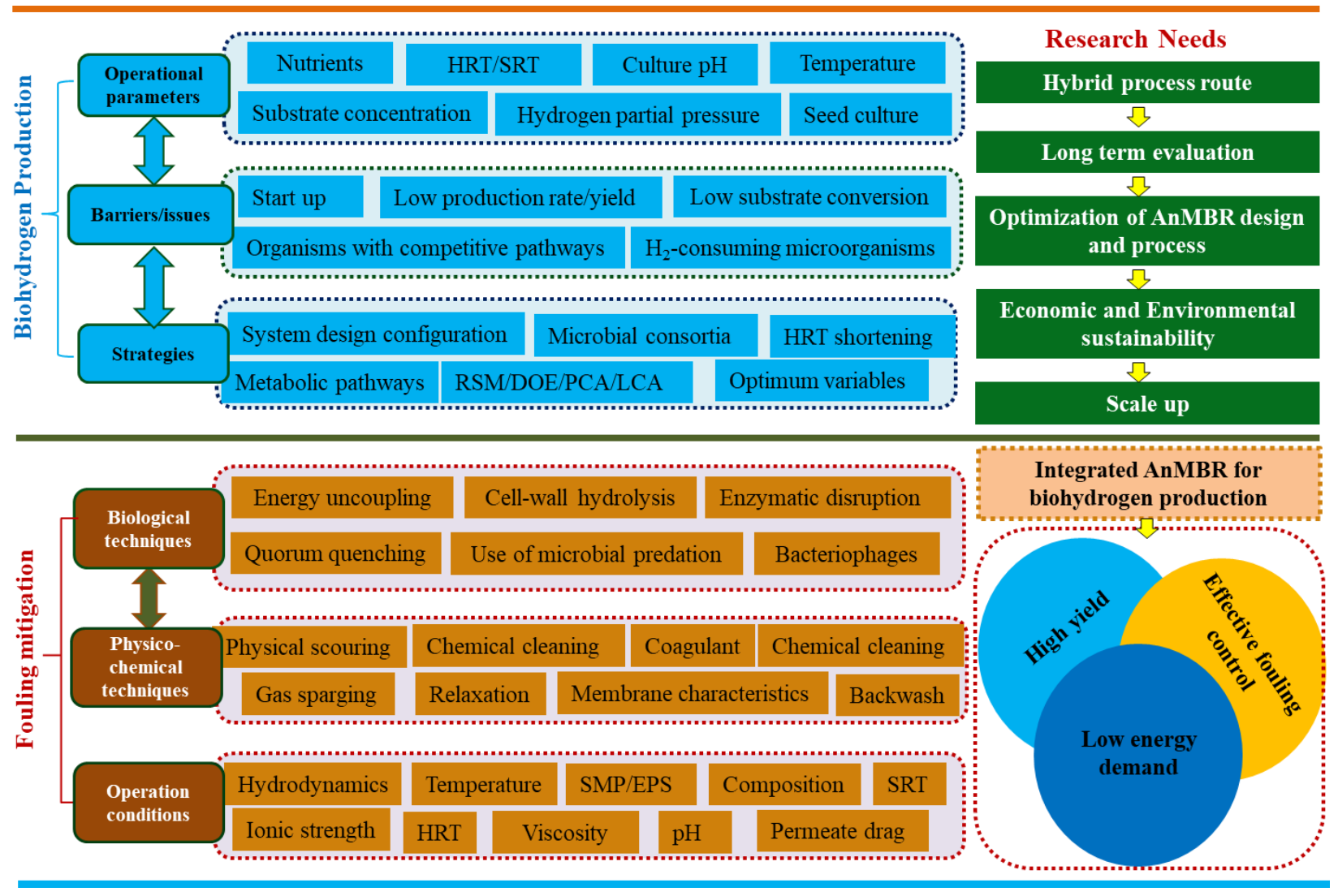

Fig. 4. Mapping of challenges, overcoming strategies and future research needs for biohydrogen production with AnMBR technology to achieve practicality and economic-feasibility

In recent years, the energy demand for fouling mitigation and membrane cost has received by far the most attention of all the contributions to operating expenditure (OPEX) trends. Membrane cost itself contributes to both capital expenditure (CAPEX) and OPEX trends. However, OPEX is related to the permeate flux and membrane life as well as strategies to employ for fouling reduction such as backwashing methods, membrane relaxations, physical 
scouring by granular materials etc. Membrane replacement component of the OPEX can contribute to $15-25 \%$ of the total cost depending on the operating conditions, membrane life and feed water quality (Gude, 2016). Membrane replacement cost trend is proportional to the ratio of the membrane cost to the membrane life times the net flux (Judd, 2017). Hence, OPEX decreases with increasing membrane life and operating flux. An increase in flux impacts both on membrane costs and specific energy demand, therefore, it has the greatest impact on OPEX. Nevertheless, immersed hollow fiber costs appear to have reached levels of $\$ 15-25 \mathrm{~m}^{-2}$ (Pearce, 2010). Another challenge is the non-standardization of the AnMBR market and non-interchangeable membrane modules. Therefore, it is unclear as to how much further cost of the traditional rigid panel of polymeric immersed flat sheet membranes can be decreased, the cost having fallen by an order of magnitude from the price range $\sim 400-500 \mathrm{~m}^{-2}$ of the early 1990`s (Judd, 2017). The new flat sheet ceramic membranes may change the paradigm of MBR membrane selection and cost trends. The predicted life of ceramic membranes is at least double that of the polymeric membranes with a purportedly higher operation flux (Ahmad et al., 2018; Niwa et al., 2016). As aforementioned, there is parity of the OPEX between membrane life and flux, for example, if ceramic material costs the four times as much, however, lasts twice as long and operates at double the flux of the polymeric materials (Judd, 2017). The current cost of Metawater multichannel monolith membrane material seems to be in the $\$ 80-160$ per $\mathrm{m}^{2}$ range, but, this may still be uncompetitive. It appears reasonable to suppose that costs will continue to fall from the $>1000 \$ / \mathrm{m}^{2}$ level of $\sim 10$ years ago in a manner analogues to that polymeric immersed flat sheet membranes 15-25 years ago (Judd, 2017). Therefore, current trends of membrane costs are declining roughly in line with improved energy efficiencies in the past decades. 


\subsubsection{Biohydrogen generation rates and yield}

The incomplete substrate conversion; the consequent low yields and generation rates are major barriers which prevent scaling-up of the process. During the biohydrogen production process, inhibitory by-products such as short chain volatile fatty acids (e.g. acetic, butyric, propionic and lactic acid, etc.), alcohols (e.g. ethanol, butanol propanol etc.) and biohydrogenconsuming microorganisms (e.g. homoacetogenesis, methanogens, nitrate-reducing bacteria, sulphate-reducing bacteria increase and lower the generation rates and yields (Das \& Veziroglu, 2008; Kotay \& Das, 2010; Mohan, 2009; Sekoai et al., 2018; Singer et al., 2018). Moreover, $60-70 \%$ of substrate is not biodegraded and remains in the form of metabolites in the effluents (Liu et al., 2002; Oh et al., 2004; Sekoai et al., 2018). This barrier means that a significant part of the chemical energy available in the fermentation raw material diverted to by-product formation and remains unexploited. However, membranes in AnMBR can retain these metabolites in the system and provide opportunity for their complete conversion to biohydrogen. Major barriers and opportunities to overcome these hurdles are shown in Fig. 4. Various strategies for enhancement of biohydrogen production have been proposed which are discussed in the section 5 .

Recent studies have already proven technical feasibility of AnMBR for biohydrogen extraction from wastewater and other wastes. The extraction of biohydrogen over methane is recognized mainly by the reason that it has a higher energy density, combining energy and environmental sustainability (Guwy et al., 2011; Kim et al., 2016). AnMBRs have different designs, bioreactor geometry, operating parameters, sludge recirculation and gas sparging in comparison to conventional CSTRS counterparts (Lee et al., 2009a). Gas bubbling not only helps mixing and fouling control but also can remove generated biohydrogen from aqueous phase by 
enhancing the liquid to gaseous mass transfer rate, which is desirable in fermentative hydrogen production since hydrogenase activity can be sensitive to increasing hydrogen concentration in the aqueous phase (Bakonyi et al., 2013b; Hallenbeck, 2009; Nath \& Das, 2004; RamírezMorales et al., 2013; Yasin et al., 2014). AnMBR facilitates the operation at short HRT and previous reports revealed that biohydrogen production rate is increased by reducing the HRT (Lee et al., 2009a; Lee et al., 2007; Oh et al., 2004). The partial pressure of hydrogen reduces the generations of alcohols and organic acids if the production of hydrogen is maximized (Adekunle \& Okolie, 2015). Therefore, it is challenging to improve hydrogen production in single-stage AnMBR. Since it also provide potential benefits to be coupled with dark fermentation or

photofermentation as two stage hydrogen generation to remove suspended solids inhibitors of photo fermentation (Eroğlu et al., 2006). AnMBR is an emerging option for biohydrogen production since it provides more robust and consistent operating possibilities.

\section{Factors affecting biohydrogen production in AnMBRs}

Biohydrogen production rates and yields are a function of several parameters including nutrient availability, HRT, SRT, pH, temperature and substrate concentration (Fig. 4). Factors affecting performance of AnMBRs during biohydrogen production are discussed in this section.

\subsection{Nutrient loading}

The availability of nutrients such as nitrogen, phosphate and other inorganic trace minerals is decisive concern not only in AnMBRs but also in all types of bioreactors. In order to obtain optimal microbial growth and biohydrogen production, minor elements supplementation is required particularly for carbohydrate-rich wastewater and other waste streams. Nutrients depending on their concentration can strongly affect the hydrogen production in AnMBRs. It was 
found that organic nitrogen appears to be more favorable in biohydrogen generation than inorganic one (Show et al., 2011). The iron concentration as a mineral salt medium is a key variable since it can either suppress or enhance the hydrogen production in AnMBR. Iron mediates between hydrogenase and NADH-ferredoxin reductase. Under low concentration of iron, hydrogenase may not efficiently mediate a reversible reaction between an electron donor (such as ferredoxin) and hydrogen. Hence, biohydrogen production from microbes can be affected by the catalytic activity of the hydrogen producing enzyme. Previous study reported that biohydrogen production was 1.59 times higher when concentration of $\mathrm{FeSO}_{4}$ was increased from 2.7 to $10.9 \mathrm{mg} / \mathrm{L}$ and hydrogen yield increased in parallel with hydrogen production rate between concentration of 2.7 and $13.7 \mathrm{mg} \mathrm{FeSO}_{4} / \mathrm{L}$ in AnMBR (Lee et al., 2009b). However, iron concentration should not exceed above a certain tolerable value otherwise strains get over loaded and subsequently poisoned which can reduce biohydrogen generation efficiency (Bakonyi et al., 2014). Another study investigated the effect of trace elements including $\mathrm{K}, \mathrm{Fe}, \mathrm{Na}, \mathrm{Mg}, \mathrm{Zn}, \mathrm{Co}$, $\mathrm{NH} 4+, \mathrm{Mn}, \mathrm{Ni}, \mathrm{Cu}, \mathrm{Ca}$ and $\mathrm{Mo}$ on biohydrogen production. The results demonstrated that $\mathrm{Na}$, $\mathrm{Zn}, \mathrm{Mg}$ and Fe were important supplements to affect the hydrogen production. They proposed an optimum nutrient formulation comprising (mg/L) $\mathrm{NaCl} 1000, \mathrm{ZnCl}_{2} 0.5, \mathrm{MgCl}_{2} \cdot 6 \mathrm{H}_{2} \mathrm{O} 120$ and $\mathrm{FeSO}_{4} .7 \mathrm{H}_{2} \mathrm{O} 3$ for optimum hydrogen yield (Lin \& Lay, 2005). However, lower value of iron and less effect of $\mathrm{NH}_{4}{ }^{+}$concentration observed in this study was inconsistent with those values proposed in other studies (Lin \& Lay, 2005; Wang \& Wan, 2009).

\subsection{Hydraulic retention time and solid retention time}

Conventionally, many studies have used CSTRs in which HRT controls the microbial growth rate and operational behavior of the system. Therefore, HRT must be greater than the maximum growth rate of the microorganisms otherwise biomass washout would be a potential 
threat by the dilution rate created via continuous volumetric flow (Hallenbeck \& Ghosh, 2009). However, membranes in AnMBR, compared with the CSTR, provide solid-liquid separation and can retain the biomass in the system, thus permit decoupling of HRT and SRT (Noblecourt et al., 2017). Previous studies reported that hydrogen production rate was increased in AnMBR while methanogenesis was inhibited or terminated by reducing HRT; nonetheless, the specific biohydrogen generation rate remained unimproved (Lee et al., 2009a; Lee et al., 2007; Oh et al., 2004). In addition, shortening HRT would reduce microbial diversity concomitant to inhibition of propionate generation without affecting the dominant species, resulting in an increase in the biohydrogen yield (Lee et al., 2014; Mohan, 2009). Biohydrogen producing microorganisms prefer relatively short hydraulic retention time. Moreover, variations in HRT can change the loading of the nutrients, which could alter the substrate utilization efficiency and associated AnMBR performance for biohydrogen production as well (Yang \& Li, 2018). As aforementioned, proliferation rate of the non-useful bacteria (propionic acid and methanogenic strains) cannot complete and much lower than that of biohydrogen producing cells; therefore, short HRT suppresses biohydrogen consuming activity and robust biohydrogen evolver bacteria can be enriched in that way and sustain in longer terms. Recently it was surveyed that efficient biohydrogen production from liquid waste streams (wastewater) as substrate would be conducted using the optimal HRT ranges from 0.5-12 h (Lin et al., 2012; Sivagurunathan et al., 2016).

Biohydrogen productivity from bacteria retention by membrane might be suppressed due to catalytic activity reduction under the long cell retention time (Lee et al., 2009a). Consequently, the formation of extracellular polymer substances (EPS) is usually higher at long SRTs and accumulation of such metabolic side-products may be attributed to inhibition of biohydrogen evolution (Lee et al., 2010a). Nevertheless, reported studies are inconsistent 
regarding the optimal SRT. For example, Lee et al. (2010a) found that 90 days SRT was unfavorable, however, in another study authors reported that no adverse effect on biohydrogen production was observed even system was operated at elevated SRT of 450 days in AnMBR (Lee et al., 2008). These results demonstrated that there is a need to determine appropriate SRT for the system and case specific considering all operational variables. Moreover, changes in SRT may lead to microbial diversity in the system, which can not only accelerate the proliferation of hydrogen producing bacteria but also competitive hydrogen consuming microbes that would lead to a different biohydrogen production efficiency (Oh et al., 2004). Nonetheless, none of the work has reported these complex interactions and community aging along with SRT deviations, hence AnMBR applications should be explored to a wider recognition for biohydrogen production.

\subsection{Reactor design}

Reactor design and process is a key parameter in biohydrogen production because it can affect the microenvironment of the system, hydrodynamic behavior, prevailing microbial population and their contact with the substrate (Trad et al., 2015b). As aforementioned, most of studies tested CSTRs as it provides perfect mass transfer as well as contact between the microorganisms and the substrate. However, often biomass even be wash out from the system at shorter HRT, leading to lower biohydrogen generation rates. In contrast, AnMBR provide better biomass concentration in the system, hence greater conversion of substrate, less sludge production due to biomass decay in the system and microorganisms free effluent (i-e high quality). Few investigations reported that overall biohydrogen production in AnMBR under

steady state operation marginally exceeds of that of CSTR (Kim et al., 2011b; Lee et al., 2008; Singer et al., 2018). However, an intensive research is needed to conclude on the solid grounds due to limited number of studies on this aspect employing AnMBRs for biohydrogen generation. 


\subsection{Substrate concentration}

The improvement in the biohydrogen production performance of AnMBR in comparison to CSTR, both in terms of production rates and yields, is the prime goal of research under different operational conditions such as various loading rates of substrate. Comparative study was performed to evaluate the performance of CSTR and AnMBR under different organic loading rates (OLR) and; hydrogen yield and production rate was observed lower in AnMBR mode (Shen et al., 2009). Recently, Saleem et al. (2018) investigated the effect of substrate concentration on biohydrogen production in side-stream anaerobic dynamic membrane bioreactor. The results demonstrated that high influent chemical oxygen demand (COD) concentrations (above $30 \mathrm{~g} / \mathrm{L}$ ) associated with high OLR favored the accumulation of volatile fatty acids (VFA) leading to the inhibition of biohydrogen generation. The stable hydrogen production was achieved by operating the system at low influent COD concentration varying in the range of 10-30 g/L and at HRT of approximately 1 day. Another study reported that gradual increase in OLR from 4 to 22 gCOD/L.d aided the hydrogen production, but OLR levels higher than $30 \mathrm{gCOD} / \mathrm{L} . \mathrm{d}$ instigated a $20 \%$ decrease in the hydrogen production performance (Shen et al., 2010). It implicates that when substrate and/or organic material loading exceeds a threshold value, the substrate and product inhibitions due to shifts in the metabolic flux towards solventogenesis and other reduced end products would occur, which are unfavorable for biohydrogen production (Cheng et al., 2011). In contrast, Lee et al. (2007) reported better performance of AnMBR operation over a wide range of OLRs. In another investigation, Lee et al. (2014) operated AnMBR with three different OLRs of 7.02, 89.4 and $125.4 \mathrm{kgCOD} / \mathrm{m}^{3} . \mathrm{d}$. The results demonstrated that hydrogen production was significantly improved by increasing the OLR and the maximum hydrogen yield and production rate were $111.1 \mathrm{~mL} \mathrm{H}_{2} / \mathrm{g}$.VS $\mathrm{Vadded}_{\text {and }}$ 
10.7 L-H $/ 2$ L.d at an OLR of $125 \mathrm{kgCOD} / \mathrm{m}^{3}$.d. Authors implied that AnMBR showed biohydrogen production capacity at the higher OLRs due to higher cell retention (Lee et al., 2014). The results reveal that there is no universal optimal OLR and it may vary with the particular inoculum, substrate and traits of the system. Nevertheless, relevant studies on this matter did not provide certain answers yet, whether AnMBR could lead to prevailing biohydrogen generation capacities when operating with different substrate concentrations.

\subsection{Temperature and $\mathrm{pH}$}

Temperature is the key variable for biohydrogen production, which potentially affects the hydrogenase activity, microbial communities and their metabolism and a spectrum of products. It is noteworthy, although hydrogen producing microorganisms are able to generate hydrogen at conditions of ambient temperature; hydrogen production performance always improves by increasing temperature in the mesophilic regime. However, hydrogen generation may be affected by further increase in temperature beyond mesophilic range, probably depending on the physiological properties of microbial culture (Show et al., 2011). Biohydrogen production performance can be promoted at high temperature by decreasing the hydrogen solubility in the broth, enhancing hydrolysis and limiting activity of propionic acid and methane producers. Temperature effect was also confirmed by Chang and Lin (2004) by studying the hydrogen production efficiency of a mixed culture with temperature varying from 15 to $34{ }^{\circ} \mathrm{C}$. In another study, temperature shift strategy was applied and biohydrogen production yield was increased by $62 \%$ because of the temperature switching from $37{ }^{\circ} \mathrm{C}$ to $45^{\circ} \mathrm{C}$ for $8 \mathrm{~h}$ (Sivagurunathan et al., 2014). The results testified that hydrogen yield and specific hydrogen production rate as well as concomitant microbial growth rate increased with temperature and were accompanied by variation of the metabolic product distribution (Chang \& Lin, 2004). The pros and cons need to 
be assessed in depth to reveal whether the higher energy investment (heating demand) for operation maintenance would compensate with the enhanced hydrogen turnouts.

Similarly, metabolic pathway, cell morphology and structure, microbial population shift and yield of biohydrogen, are also strongly associated with $\mathrm{pH}$ as it is considered as one of the important variable in environmental conditions. The $\mathrm{pH}$ remarkably affects and able to limit the methanogen growth because propionogenesis and methanogenesis are undesired phenomena in biohydrogen process due to their biohydrogen consuming characteristics (Hernandez-Mendoza et al., 2014; Sivagurunathan et al., 2016). Some studies reported that cultivation pH below 4.5 significantly eliminate the biohydrogen consuming methanogens. Extensive literature review revealed that optimum $\mathrm{pH}$ value during continuous fermentative hydrogen production to achieve the specific production rate or maximum hydrogen yield was observed in most studies between 5.2 and 6.0 using pure or mixed microbial culture (Oh et al., 2004; Show et al., 2011). Chang and Lin (2004) found higher production rate and yield at $\mathrm{pH}$ of 5.7 than that of operation conducted at pH 6.4 under identical conditions. In contrast, Mohan (2009) reported the acceptable ranges of $\mathrm{pH}$ for hydrogen production between 5.5 and 7.5 , whereas the hydrogen evolution yield may be suppressed at out of the optimum range. Another study revealed that optimum $\mathrm{pH}$ range may vary depending on the physiological characteristics of substrate and composition of microbial population (Méndez-Contreras et al., 2016; Wang \& Wan, 2009). Thus, much additional fundamental work is required before practically useful biohydrogen generation with AnMBR technology.

\subsection{Seed culture}

Biohydrogen can be produced using pure or mixed cultures. Pure culture is recognized by high selectivity and hydrogen production capabilities because metabolism of microorganisms can 
be easily manipulated by changing growth and operational conditions. However, most of studies using pure culture were conducted in batch mode and consequently required aseptic environment, thus increased overall cost. From the engineering perspective, mixed cultures from anaerobic sludge, municipal sewage sludge compost and soil as inoculum are desirable to use, presumably applied in most of studies for fermentative hydrogen production (Kim et al., 2006; Li \& Fang, 2007; Show et al., 2011). In addition, mixed consortia are robust under non-sterile conditions and able to support a variety of metabolic activities as well as potentially more resilient to changes in environmental conditions. However, mixed consortia might contain bacteria which do not produce hydrogen but complete for carbon source. Therefore, appropriate operational conditions or pretreatment step is required to get rid of the competing bacteria and enhance dominance of hydrogen producing bacteria (Hallenbeck \& Ghosh, 2009; Hung et al., 2011; Sivagurunathan et al., 2016).

\subsection{Hydrogen partial pressure}

The hydrogen partial pressure caused by the dissolved hydrogen concentration in the liquid phase is one of the bottlenecks in fermentative hydrogen production. An increase in partial pressure shifts microbial pathways and metabolic flux as well as simultaneously increased formation of lactate and other solvents (such as ethanol, acetone butanol etc.), thus suppressing the overall biohydrogen yield. Many techniques are now being used to overcome negative impact of hydrogen partial pressure (Lee et al., 2012). An increase in yield was observed up to 65\% by sparging the system with nitrogen (Mizuno et al., 2000). Another study reported 1.5 times enhanced biohydrogen yield when the nitrogen sparging was carried out in the system. However, the purity of biohydrogen is affected because of dilution impact which is a major limitation of gas purging strategy. In another study, Lee et al. (2012) applied vacuum strategy to reduce 
generation pressure and to improve biohydrogen rate. The results demonstrated that reduced pressure of $380 \mathrm{mmHg}$ improve more than $8 \%$ increase in biohydrogen production rate in comparative to $780 \mathrm{mmHg}$ conditions under $12 \mathrm{~h}$ HRT (Lee et al., 2012). The increase in biohydrogen yield might be attributed to thermodynamics under lower hydrogen partial pressure, which affected NADH hydrogenase, lactate hydrogenase and homoacetogenesis reactions (Hussy et al., 2003). In addition to gas sparging and vacuum, recently some studies emphasized on the installation of gas separation membranes where biohydrogen was continuously extracted from the gaseous mixture to keep the hydrogen partial pressure sufficiently low. It implies that evolved biohydrogen can be recovered, purified along with accomplishing upstream and downstream stages in single stage (Bakonyi et al., 2013a; Bakonyi et al., 2015; Saqib et al., 2018).

\section{Techniques to improve biohydrogen production}

Recently, biological hydrogen production has increased scientific attention because of its potential for inexhaustible, low cost and renewable source of clean energy. Among all production technologies, anaerobic hydrogen fermentation seems to be most favorable since hydrogen can be generated at higher rates. In addition, various wastewaters and organic wastes enriched with carbohydrates can be treated in this process, thereby achieving sustainable low cost biohydrogen production with concomitant waste minimization (Show et al., 2011). To date, most of reports demonstrated biohydrogen production at laboratory-scale, however, efficiency, cost and reliability of AnMBR technology is yet to compete with conventional CSTRs and commercial hydrogen production processes from fossil fuels. Thus, improving the bioproduction generation efficiency poses a major challenge to this technology. 


\subsection{Reactor design and configuration}

Biohydrogen production could be possibly improved through specialized reactor design and configurations. Reactor configuration can be suitable that would stable over long period of operation time and resistance to short term fluctuations in operational parameters. Consequently, optimized volumetric production rates could be obtained. The critical assessment of the literature revealed that AnMBR technology is able to compete with CSTRs. Specific biohydrogen production rates and/or biohydrogen yields would appear slightly better with CSTR, whereas Lee et al. (2007) reported that AnMBR presumably allows achieving relatively increased volumetric hydrogen production rates. However, some studies found that overall hydrogen generation performance of AnMBR under steady state operation fairly exceeds of that of the CSTR (Kim et al., 2011b; Lee et al., 2008). Recently, Noblecourt et al. (2017) observed average and maximum productivities of 0.75 and 2.46 L-H $/$ L.h in AnMBR, which were 44 and 51\% higher respectively in comparison to control system without membrane. Furthermore, AnMBR may provide a more robust and consistent operating possibility. The results have also been encouraging with multi stage design and configurations. Recent investigation employed concept of coupling a continuous hydrogen fermenter with integrated membrane system. They achieved $1.13 \mathrm{~mol} \mathrm{H}_{2} / \mathrm{mol}$ glucose yield and $0.24 \mathrm{~mol} \mathrm{H}_{2} / \mathrm{L}$.d production rate under different HRTs of 12 to $92 \mathrm{~h}$ (Bakonyi et al., 2015). Usually, initial hydrolysis/acidogenesis and final acetogenesis/methanogenesis stages are applied in two stage anaerobic digestion configurations, where different operating condition of $\mathrm{pH}$ and temperature are employed separately depending on the growth rate of microorganisms in individual stages. The heat shock and load shock treatment is applied in the initial stage for the selective inhibition of methanogens to maximize 
the biohydrogen production (Jariyaboon et al., 2015; Khan et al., 2016; Paudel et al., 2014; Singh \& Wahid, 2015).

Recently, Bakonyi et al., (2017) developed a novel gas separation integrated membrane bioreactor (GSMBR) configuration to evaluate the impact of self-generated biogas recycling to improve biohydrogen production performance. They stripped the fermentation liquor with $\mathrm{CO}_{2}$ and $\mathrm{H}_{2}$ enriched gases obtained directly from the system bioreactor headspace. The results demonstrated that sparging the bioreactor with $\mathrm{CO}_{2}$ enriched fraction enhanced the steady state biohydrogen production of 8.9-9.2 $\mathrm{L}-\mathrm{H}_{2} / \mathrm{L} . \mathrm{d}$ in comparison to membrane-less control CSTR to be regarded with 6.96-7.35 L- $\mathrm{H}_{2} / \mathrm{L}$.d values. In contrast, purging with $\mathrm{H}_{2}$ enriched gas strongly suppressed the achievable biohydrogen evolution (2.7-3.03 L-H L $_{2}$ L.d) (Bakonyi et al., 2017). Nevertheless, the overall energy extraction could also be maximized by employing photofermentation and microbial electrolysis cell (MECs) as the second stage of anaerobic hydrogen fermentation (Kapdan \& Kargi, 2006; Wang et al., 2011). The effluent of hydrogen producing system is fed to second stage and additional hydrogen from the metabolites of the dark fermentation can be recovered using two stage configurations. The synergy of the multi-stage configuration lies in the maximum substrate utilization because of improved thermodynamics. The biomass is fermented to hydrogen, acetate and carbon dioxide in a thermophilic dark fermentation at first stage. In second stage, acetate is converted to hydrogen and carbon dioxide (Nath \& Das, 2006; Paudel et al., 2014). Recently, novel configuration of tubular anaerobic electrochemical membrane bioreactor (AnEMBR) with nickel-based conductive hollow fiber membranes (Ni-HFMs) for treatment of low-organic strength solutions was developed by Katuri et al. (2014). Here, Ni-HFMs were applied as cathode to enhance hydrogen evolution reaction and functionality for membrane filtration. This dual functional cathode has advantages for both 
cost and foot-print reductions (Katuri et al., 2014). Later on, Werner et al. (2016) developed rectangular AnEMBR with electrically conductive graphene coated porous hollow fiber membrane (Gr-HFMs) as cathode and compared its performance with tubular configuration. The results demonstrated that hydrogen production rates in the rectangular AnEMBR were the higher and reached $0.21 \pm 0.05 \mathrm{~m}^{3} \mathrm{H}_{2} / \mathrm{m}^{3} . \mathrm{d}$ at $0.7 \mathrm{~V}$ and $0.41 \pm 0.08 \mathrm{~m}^{3} \mathrm{H}_{2} / \mathrm{m}^{3} . \mathrm{d}$ at $0.9 \mathrm{~V}$ than that of tubular one where rates of hydrogen production were low averaging $0.01 \pm 0.01 \mathrm{~m}^{3} \mathrm{H}_{2} / \mathrm{m}^{3}$.d. Additionally, rectangular AnEMBR configuration with Gr-HFMs outperformed tubular one in terms of biofouling mitigation and biohydrogen bubbling reduced fouling by more than $70 \%$ with it than that with tubular one at same applied voltage (Werner et al., 2016). While is the research so far have indicated encouraging findings, inventive AnMBR models at laboratory to pilot-scale need to be designed to produce biohydrogen only to identify its specific potential benefits.

\subsection{Microbial consortia}

The use of mixed microbial consortia instead of pure culture could enhance biohydrogen extraction because they are likely to contain a suite of the necessary hydrolytic activities and are potentially more robust against variations in process and environmental conditions (such as $\mathrm{pH}$, temperature, growth nutrients) (Kleerebezem \& van Loosdrecht, 2007; Wang \& Wan, 2009; Wong et al., 2014). As aforementioned, there is no microbial diversity in pure culture unlike mixed cultures; therefore, metabolic pathways are easily detected. The studies using pure culture can reveal optimized conditions that enhance biohydrogen yields. However, pure cultures require stringent bioprocess conditions and have high risks of contamination as well as utilize limited substrates. Hence, pure culture may escalate the process costs at scale-up production (Elsharnouby et al., 2013). In contrast, Mixed microbial consortia facilitate an economic 
feasibility because it can provide synergistic relationship between microorganisms and process can utilize different substrates. Additionally, there are no aseptic techniques required as well as there is possibility of co-fermeting different substrates and higher substrate conversion efficiency (Dinesh et al., 2018). However, hydrogen consuming microorganisms, such as hydrogenotrophic methanogens and sulphur utilizing, also present in mixed culture. Therefore, specific reactor operating conditions such as acidic or pretreatment of inoculum using different chemical and physical techniques have usually been employed in order to enhance biohydrogen productions rates and yields (Giordano et al., 2014; Spagni et al., 2010; Wang \& Wan, 2009). The pretreatment is used to enrich the composition of biohydrogen producers in mixed bacterial communities and to inhibit the biohydrogen consuming microorganisms such as homoacetogens and methanogens, which are prevalent in mixed microbial communities (Salem et al., 2018; Seidl \& Goulart, 2016). Their compositions as complex consortia can vary over time with changes in process parameters and a possible way to overcome this concern might be to construct 'designer' consortia to create a community of diverse members (Brenner et al., 2008). A unique and essential metabolic capacity can be contributed by each member and total community metabolic range would be greater than that of any individual member. Meanwhile, stable maintenance of individual members may be assured by mutual interdependence at the same time (Brenner et al., 2008). However, a little information is known about how stable synthetic microbial communities could be built or understanding of complex interactions which occur in natural hydrogen producing consortia. It appears that spatial organization within a consortium might be imperative (Hallenbeck \& Ghosh, 2009). Nevertheless, inoculum acclimated to a certain substrate in conventional bioreactor and/or CSTR seems beneficial before switching to integrated operation mode of AnMBR. When washout of mixed consortia becomes a potential threat in conventional 
membrane lacking fermenter, it should be moved to AnMBR that would facilitate appropriate SRT/HRT ratio which is critical in anaerobic hydrogen fermentation to improve biohydrogen production (Bakonyi et al., 2014).

\subsection{Metabolic pathways and other approaches}

Metabolic engineering is getting scientific and engineered attention to improve particularly biohydrogen yields. Increments in the flux by gene knockouts of competing pathways or increased homologues countenance of enzymes contributing in the hydrogen producing pathways appears beneficial to maximize hydrogen production through existing pathways (Hallenbeck \& Ghosh, 2009). An increase in hydrogen production is expected by the inactivation of pathways which drain the pyruvate pool which is the source of electrons for proton reduction. The inactivation of fumarate reductase $(f r d)$ or lactate dehydrogenase $(l d h A)$ resulted in 20-30\% increase in hydrogen yields (Maeda et al., 2007; Yoshida et al., 2006). Furthermore, It was reported that the inactivation of hydrogenases Hyd1 and Hyd2 increased the total amount of hydrogen produced (Hallenbeck, 2005). Hence, metabolic engineering could be applied to microorganism to take over the metabolic pathways to achieve maximum yields of hydrogen predicted.

The incomplete conversions of substrate in anaerobic hydrogen fermentation lead to the generation of a large amount of other products and about two-third of the substrate is converted to side products. Therefore, it is indispensable not only to introduce additional pathways that would countenance near stoichiometric conversion within the microbial cell but also to develop integrated two stage configuration to get complete recovery of energy preferably in the form of hydrogen rather than side products (Khan et al., 2016; Singhania et al., 2012). Microbial immobilization can also be adopted to enhance the cell mass concentration under low HRT 
conditions and biohydrogen generation performance. It can be carried out by the addition of carrier materials such as activated carbon, cell embedment, porous polymeric carriers and selfgranulation. Biohydrogen production performance may vary with carrier material, type of feed stock and operational conditions. Nevertheless, mass transfer limitation may occur in system with microbial immobilization (Sivagurunathan et al., 2016; Yasin et al., 2015). Furthermore, bioaugmentation can be considered to improve the ability of the microbial consortia to withstand the process variations and achieve higher substrate degradation efficiency. Usually, addition of sufficiently growing and specialized whole cell biocatalysts to native microbial community of the system aid start-up, to protect the existing microorganisms against inhibition effects and promote biohydrogen turnout (Mohan et al., 2007; Sivagurunathan et al., 2014). In addition, effluent recycling strategy would provide buffering capacity, low mass transfer resistance and avoiding excess alkali requirement for $\mathrm{pH}$ maintenance, resulting in biohydrogen production performance. Recently, Kim et al. (2012) recycled the methanogenic effluent to the biohydrogen reactor without any pretreatment and improved the biohydrogen productivity over $48 \%$. As a result, alkaline dosage and external dilution water by $75 \%$ was also decreased (Kim et al., 2012). Previous study suggested based on computational modeling that increasing glucose oxidation through the pentose phosphate pathway with conversion of the generated NADPH to NADH by transhydrogenase would be helpful (Jones, 2008). In addition, modeling and analysis would assist to find optimal values of relevant important parameters that have significant impact to improve production rates. To date, several modeling methods have been developed and their application in biohydrogen production have been discussed in a previous review (Wang \& Wan, 2009). For example, an investigation applied principal component analysis to study the effects of HRT, PH and mixing on hydrogen production rates (Aceves-Lara et al., 2008). Similarly, 
artificial neural networks (ANNs), design of experiments (DOE) and response surface methodology (RSM) modeling approaches could be applied that are pertinent to biohydrogen generation to investigate how responses of multiple factors depend on each other and identify the most important parameters that control the process and the degree of interactions among them to maximize biohydrogen production in AnMBRs (Guo et al., 2008; Trad et al., 2015b; Yang \& Li, 2018).

\section{Environmental and economic assessment of biohydrogen production in AnMBRs}

The current hydrogen production mainly comes from fossils fuels which contribute to huge amount of greenhouse gasses in the environment. Biohydrogen production from anaerobic digestion could be vital to reduce $\mathrm{CO}_{2}$ emissions from fossil fuels. In the current scenario, AnMBR is a potential emerging technology widely used in anaerobic digestion to convert wastewater into methane. However, methane and its combustion product still widely contribute to greenhouse gas emissions and could not be worthy as a sustainable and renewable product from wastewater and other waste streams via AnMBR. Other possible route for the system is biohydrogen production which contains no environmental harm as an energy source (produce only $\mathrm{H}_{2} \mathrm{O}$ as a combustion product) and has very little environmental impact when compares with other AnMBR products e.g. volatiles fatty acid (VFA) and methane (Khan et al., 2016). In this regard, biohydrogen production from AnMBR could be one vital alternative to make the emerging technology as pilot/commercial success with no harm to the environment. Some limited research models have been developed for biohydrogen production in AnMBR systems. Guwy et al. (2011) proposed a two-stage anaerobic digestion system with limitation of COD and organic loading rate to treat sewage sludge, wastewater, food waste and agro-industrial wastes. Smith et al. (2014) evaluated emerging AnMBR technology in comparison with conventional 
wastewater energy recovery technologies (such as high rate activated sludge with anaerobic digestion, conventional activated sludge with anaerobic digestion, aerobic MBR with anaerobic digestion). Modeling and system analysis were combined for evaluations and observations revealed that AnMBR may have lower life cycle environmental emissions and produce more net energy as compared to high rate activated sludge with anaerobic digestion, conventional activated sludge with anaerobic digestion and aerobic MBR (Fig. 5). Future developments in low fouling control, of AnMBR technology, higher flux and management of greenhouse gases emissions would make AnMBR competitive to high rate activated sludge with anaerobic digestion process. The development of the process is still in its infant stage and extensive theoretical and experimental work is required to evaluate the technical, economic and environmental feasibility through installation cost, energy consumption and wide operability in AnMBR applications (Fig.4).

One of the economic hurdles of AnMBR is high initial installation and operating cost compared to low energy recovery which is mainly contributed to low hydrogen yield in anaerobic digestion processes. The possible overcome to this can be multiple product streaming e.g. biohydrogen and/or methane, methane and VFA to compensate the high initial cost to the process. Besides the additional cost (recycling of biogas for fouling control which requires 50-70 $\%$ of total operational cost of AnMBR) to the process, AnMBR shows robustness and wide operation possibility as compared to different bioreactors systems (Bakonyi et al., 2015).

The inherent problems associated with AnMBR and anaerobic fermentation needs to be accepted for biohydrogen production to develop feasibility studies with the minimal information in hand. Secondly, the public perception about the biohydrogen and its generation from 
wastewater and other waste streams through anaerobic fermentation in AnMBR needs to be addressed through environmental impact and economical assessments.

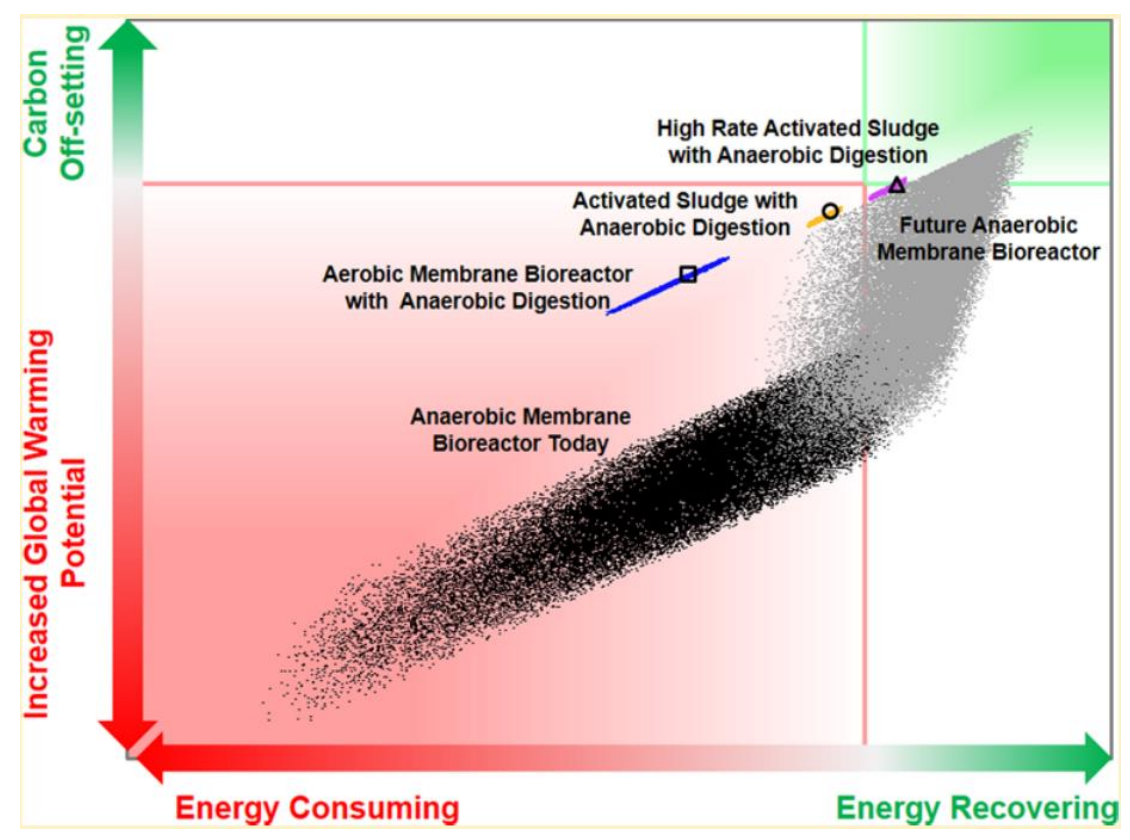

Fig. 5. Global warming potential versus energy balance for AnMBR technology in comparison to high rate activated sludge with anaerobic digestion, conventional activated sludge with anaerobic digestion, aerobic membrane bioreactor with anaerobic digestion. Reprinted with permission from Ref. Smith et al. (2014). Copyright 2014 American Chemical Society.

\section{Future perspectives}

The relatively low biohydrogen production rate, yield and membrane fouling in anaerobic membrane bioreactors are three major challenges remains to be overcome before a feasible practical process. The substantial improvements in fouling control, volumetric productions rate and yield may be possible by employing efficient reactor design and configuration, process modification, suitable microbial strain, metabolic and genetic engineering to redirect metabolic pathway (See Fig. 4). Some integrated approaches may also be feasible such as two stage process or the use of modified combined configuration of AnMBR and 
microbial fuel cell or anaerobic electrochemical membrane bioreactor in attempting to address these limitations in future research.

The improvement in biohydrogen yields of microbial cultures with higher production rates might also be another conceivable route by applying genetic and metabolic engineering techniques. Yet, to be practical, yields must noticeably extend past the present metabolic restraint of $4 \mathrm{H}_{2} /$ glucose. The major question that must be answered, 'is it possible to extract nearly all hydrogen of $12 \mathrm{H}_{2} /$ glucose from substrate through development of a practical biological process?' Therefore, future studies on biohydrogen production research particularly in hybrid AnMBR technology should focus to attempt addressing this challenge. It would be impossible to find a microorganism capable to convert all of the substrates by anaerobic hydrogen fermentation as suggested by thermodynamics and metabolic constraints (Hallenbeck, 2005; Thauer et al., 1977), therefore, human mediation is required to address this concern. Otherwise, economic feasibility of anaerobic hydrogen fermentation will not be sustainable at lower level of yield because dark fermentative bacteria only produce small amount of hydrogen usually stoichiometrically less than 30\% (Ren et al., 2011; Show et al., 2011). In addition, technical challenges towards practicality and economic feasibility in potential of AnMBR in biohydrogen generation include lowering the energy demands and cost of fouling control and hydrogen production, storage, conversion, delivery and end usages. Economic and environmental sustainability would intensely indulgence large scale AnMBR hydrogen productions systems (Fig. 4). A significant effort is underway in developing low energy-demanding fouling control systems such as anaerobic fluidized bed membrane bioreactor, anaerobic dynamic membrane bioreactors, anaerobic electrochemical membrane bioreactors etc. and improving further hydrogen production capacity using metabolic engineering approach. With technology advances, 
AnMBRs may offer a sustainable potential of biohydrogen production and alternative avenue of energy research from wastewaters and other waste organic streams as resource in future.

\section{Conclusions}

The potential of biohydrogen production in AnMBRs could provide an attractive future energy carrier due to its potentially higher efficiency of conversion to usable power, high energy density and low generation of pollutants. The substantial improvement and development in both the yield and production rates of biohydrogen fermentations surpass considerably by employing integrated system with mixed microbial consortia and metabolic engineering. Considering the practicality and economic feasibility of biohydrogen generation with AnMBRs, technology breakthrough must be sought to refine better performances in terms of reduced energy consumption and fouling; extract most of hydrogen from substrate and scaling up of the longterm steady state operation.

\section{Acknowledgements}

This research was supported by Basic Science Research Program through the National Research Foundation of Korea (NRF) funded by the Ministry of Science \& ICT (2017RA1A2B4007804). This work was supported by the new faculty research fund of Sejong University in 2008.

\section{References}

1. Aceves-Lara, C.A., Latrille, E., Buffiere, P., Bernet, N., Steyer, J.-P. 2008. Experimental determination by principal component analysis of a reaction pathway of biohydrogen production by anaerobic fermentation. Chemical Engineering and Processing: Process Intensification, 47(11), 1968-1975.

2. Adekunle, K.F., Okolie, J.A. 2015. A review of biochemical process of anaerobic digestion. Advances in Bioscience and Biotechnology, 6(03), 205.

3. Ahmad, R., Ahmad, Z., Khan, A.U., Mastoi, N.R., Aslam, M., Kim, J. 2016. Photocatalytic systems as an advanced environmental remediation: Recent developments, limitations and new avenues for applications. Journal of Environmental Chemical Engineering, 4(4), 4143-4164.

4. Ahmad, R., Aslam, M., Park, E., Chang, S., Kwon, D., Kim, J. 2018. Submerged low-cost pyrophyllite ceramic membrane filtration combined with GAC as fluidized particles for industrial wastewater treatment. Chemosphere. 
5. Akinbomi, J., Wikandari, R., Taherzadeh, M.J. 2015. Enhanced fermentative hydrogen and methane production from an inhibitory fruit-flavored medium with membrane-encapsulated cells. Membranes, 5(4), 616-631.

6. Aslam, M., Ahmad, R., Kim, J. 2018a. Recent developments in biofouling control in membrane bioreactors for domestic wastewater treatment. Separation and Purification Technology, 206, 297-315.

7. Aslam, M., Charfi, A., Kim, J. 2017a. Membrane scouring to control fouling under fluidization of nonadsorbing media for wastewater treatment. Environ Sci Pollut Res Int, 1-11.

8. Aslam, M., Charfi, A., Lesage, G., Heran, M., Kim, J. 2017b. Membrane bioreactors for wastewater treatment: A review of mechanical cleaning by scouring agents to control membrane fouling. Chemical Engineering Journal, 307, 897-913.

9. Aslam, M., Kim, J. 2017. Investigating membrane fouling associated with GAC fluidization on membrane with effluent from anaerobic fluidized bed bioreactor in domestic wastewater treatment. Environ Sci Pollut Res Int, 1-11.

10. Aslam, M., Lee, P.-H., Kim, J. 2015. Analysis of membrane fouling with porous membrane filters by microbial suspensions for autotrophic nitrogen transformations. Separation and Purification Technology, 146, 284-293.

11. Aslam, M., McCarty, P.L., Bae, J., Kim, J. 2014. The effect of fluidized media characteristics on membrane fouling and energy consumption in anaerobic fluidized membrane bioreactors. Separation and Purification Technology, 132, 10-15.

12. Aslam, M., McCarty, P.L., Shin, C., Bae, J., Kim, J. 2017c. Low energy single-staged anaerobic fluidized bed ceramic membrane bioreactor (AFCMBR) for wastewater treatment. Bioresource Technology, 240, 3341.

13. Aslam, M., Yang, P., Lee, P.-H., Kim, J. 2018b. Novel staged anaerobic fluidized bed ceramic membrane bioreactor: Energy reduction, fouling control and microbial characterization. Journal of Membrane Science, 553, 200-208.

14. Bakonyi, P., Buitrón, G., Valdez-Vazquez, I., Nemestóthy, N., Bélafi-Bakó, K. 2017. A novel gas separation integrated membrane bioreactor to evaluate the impact of self-generated biogas recycling on continuous hydrogen fermentation. Applied energy, 190, 813-823.

15. Bakonyi, P., Kumar, G., Nemestóthy, N., Lin, C., Bélafi-Bakó, K. 2013a. Biohydrogen purification using a commercial polyimide membrane module: studying the effects of some process variables. international journal of hydrogen energy, 38(35), 15092-15099.

16. Bakonyi, P., Nemestóthy, N., Bélafi-Bakó, K. 2013b. Biohydrogen purification by membranes: an overview on the operational conditions affecting the performance of non-porous, polymeric and ionic liquid based gas separation membranes. international journal of hydrogen energy, 38(23), 9673-9687.

17. Bakonyi, P., Nemestóthy, N., Lankó, J., Rivera, I., Buitrón, G., Bélafi-Bakó, K. 2015. Simultaneous biohydrogen production and purification in a double-membrane bioreactor system. international journal of hydrogen energy, 40(4), 1690-1697.

18. Bakonyi, P., Nemestóthy, N., Simon, V., Bélafi-Bakó, K. 2014. Fermentative hydrogen production in anaerobic membrane bioreactors: a review. Bioresource technology, 156, 357-363.

19. Bartacek, J., Zabranska, J., Lens, P.N. 2007. Developments and constraints in fermentative hydrogen production. Biofuels, Bioproducts and Biorefining, 1(3), 201-214.

20. Bharathiraja, B., Sudharsanaa, T., Bharghavi, A., Jayamuthunagai, J., Praveenkumar, R. 2016. Biohydrogen and Biogas-An overview on feedstocks and enhancement process. Fuel, 185, 810-828.

21. Boodhun, B.S.F., Mudhoo, A., Kumar, G., Kim, S.-H., Lin, C.-Y. 2017. Research perspectives on constraints, prospects and opportunities in biohydrogen production. International Journal of Hydrogen Energy, 42(45), 27471-27481.

22. Brenner, K., You, L., Arnold, F.H. 2008. Engineering microbial consortia: a new frontier in synthetic biology. Trends in biotechnology, 26(9), 483-489.

23. Chang, F.-Y., Lin, C.-Y. 2004. Biohydrogen production using an up-flow anaerobic sludge blanket reactor. International Journal of Hydrogen Energy, 29(1), 33-39.

24. Charfi, A., Aslam, M., Kim, J. 2018a. Modelling approach to better control biofouling in fluidized bed membrane bioreactor for wastewater treatment. Chemosphere, 191, 136-144.

25. Charfi, A., Aslam, M., Lesage, G., Heran, M., Kim, J. 2017a. Macroscopic approach to develop fouling model under GAC fluidization in anaerobic fluidized bed membrane bioreactor. Journal of Industrial and Engineering Chemistry, 49, 219-229. 
26. Charfi, A., Park, E., Aslam, M., Kim, J. 2018b. Particle-sparged anaerobic membrane bioreactor with fluidized polyethylene terephthalate beads for domestic wastewater treatment: Modelling approach and fouling control. Bioresource technology, 258, 263-269.

27. Charfi, A., Thongmak, N., Benyahia, B., Aslam, M., Harmand, J., Amar, N.B., Lesage, G., Sridang, P., Kim, J., Heran, M. 2017b. A modelling approach to study the fouling of an anaerobic membrane bioreactor for industrial wastewater treatment. Bioresource Technology, 245, 207-215.

28. Chawla, M., Rafiq, S., Jamil, F., Usman, M.R., Khurram, S., Ghauri, M., Muhammad, N., Ala'a, H., Aslam, M. 2018. Hydrocarbons fuel upgradation in the presence of modified bi-functional catalyst. Journal of Cleaner Production, 198, 683-692.

29. Cheng, S.-S., Chao, Y.-C., Yang, K.-H., Bai, M.-D. 2011. Process recovery of biohydrogenation in a pilot plant from methanogens invasion. international journal of hydrogen energy, 36(14), 8779-8784.

30. da Silva Veras, T., Mozer, T.S., da Silva César, A. 2017. Hydrogen: Trends, production and characterization of the main process worldwide. International journal of hydrogen energy, 42(4), 20182033.

31. Das, D., Veziroglu, T.N. 2008. Advances in biological hydrogen production processes. International journal of hydrogen energy, 33(21), 6046-6057.

32. Davila-Vazquez, G., Arriaga, S., Alatriste-Mondragón, F., de León-Rodríguez, A., Rosales-Colunga, L.M., Razo-Flores, E. 2008. Fermentative biohydrogen production: trends and perspectives. Reviews in Environmental Science and Bio/Technology, 7(1), 27-45.

33. Deng, L., Guo, W., Ngo, H.H., Zhang, H., Wang, J., Li, J., Xia, S., Wu, Y. 2016. Biofouling and control approaches in membrane bioreactors. Bioresource technology, 221, 656-665.

34. Dinesh, G.K., Chauhan, R., Chakma, S. 2018. Influence and strategies for enhanced biohydrogen production from food waste. Renewable and Sustainable Energy Reviews, 92, 807-822.

35. Drews, A. 2010. Membrane fouling in membrane bioreactors-characterisation, contradictions, cause and cures. Journal of Membrane Science, 363(1), 1-28.

36. Elsharnouby, O., Hafez, H., Nakhla, G., El Naggar, M.H. 2013. A critical literature review on biohydrogen production by pure cultures. International Journal of Hydrogen Energy, 38(12), 4945-4966.

37. Eroğlu, E., Eroğlu, İ., Gündüz, U., Türker, L., Yücel, M. 2006. Biological hydrogen production from olive mill wastewater with two-stage processes. International journal of hydrogen energy, 31(11), 1527-1535.

38. Gassanova, L., Netrusov, A.I., Teplyakov, V., Modigell, M. 2006. Fuel gases from organic wastes using membrane bioreactors. Desalination, 198(1-3), 56-66.

39. Ghauri, M., Bokhari, A., Aslam, M., Tufail, M. 2011. Biogas reactor design for dry process and generation of electricity on sustainable basis. International Journal of Chemical and Environmental Engineering, 2(6), 414-417.

40. Giordano, A., Sarli, V., Lavagnolo, M.C., Spagni, A. 2014. Evaluation of aeration pretreatment to prepare an inoculum for the two-stage hydrogen and methane production process. Bioresource technology, 166, 211-218.

41. Gude, V.G. 2016. Desalination and sustainability-an appraisal and current perspective. Water research, 89, 87-106.

42. Guo, W.-Q., Ren, N.-Q., Chen, Z.-B., Liu, B.-F., Wang, X.-J., Xiang, W.-S., Ding, J. 2008. Simultaneous biohydrogen production and starch wastewater treatment in an acidogenic expanded granular sludge bed reactor by mixed culture for long-term operation. International Journal of Hydrogen Energy, 33(24), 73977404.

43. Guo, X.M., Trably, E., Latrille, E., Carrere, H., Steyer, J.-P. 2010. Hydrogen production from agricultural waste by dark fermentation: a review. international journal of hydrogen energy, 35(19), 10660-10673.

44. Guwy, A., Dinsdale, R., Kim, J., Massanet-Nicolau, J., Premier, G. 2011. Fermentative biohydrogen production systems integration. Bioresource technology, 102(18), 8534-8542.

45. Hallenbeck, P. 2005. Fundamentals of the fermentative production of hydrogen. Water Science and Technology, 52(1-2), 21-29.

46. Hallenbeck, P.C. 2009. Fermentative hydrogen production: principles, progress, and prognosis. International Journal of Hydrogen Energy, 34(17), 7379-7389.

47. Hallenbeck, P.C., Benemann, J.R. 2002. Biological hydrogen production; fundamentals and limiting processes. International Journal of Hydrogen Energy, 27(11-12), 1185-1193.

48. Hallenbeck, P.C., Ghosh, D. 2009. Advances in fermentative biohydrogen production: the way forward? Trends in biotechnology, 27(5), 287-297. 
49. Hankamer, B., Lehr, F., Rupprecht, J., Mussgnug, J.H., Posten, C., Kruse, O. 2007. Photosynthetic biomass and $\mathrm{H} 2$ production by green algae: from bioengineering to bioreactor scale-up. Physiologia plantarum, 131(1), 10-21.

50. Hawkes, F.R., Hussy, I., Kyazze, G., Dinsdale, R., Hawkes, D.L. 2007. Continuous dark fermentative hydrogen production by mesophilic microflora: principles and progress. International Journal of Hydrogen Energy, 32(2), 172-184.

51. He, Y., Bagley, D.M., Leung, K.T., Liss, S.N., Liao, B.-Q. 2012. Recent advances in membrane technologies for biorefining and bioenergy production. Biotechnology advances, 30(4), 817-858.

52. Hernandez-Mendoza, C.E., Moreno-Andrade, I., Buitron, G. 2014. Comparison of hydrogen-producing bacterial communities adapted in continuous and discontinuous reactors. international journal of hydrogen energy, 39(26), 14234-14239.

53. Holladay, J.D., Hu, J., King, D.L., Wang, Y. 2009. An overview of hydrogen production technologies. Catalysis today, 139(4), 244-260.

54. Hung, C.-H., Chang, Y.-T., Chang, Y.-J. 2011. Roles of microorganisms other than Clostridium and Enterobacter in anaerobic fermentative biohydrogen production systems-a review. Bioresource technology, 102(18), 8437-8444.

55. Hussy, I., Hawkes, F., Dinsdale, R., Hawkes, D. 2003. Continuous fermentative hydrogen production from a wheat starch co-product by mixed microflora. Biotechnology and bioengineering, 84(6), 619-626.

56. Iorhemen, O.T., Hamza, R.A., Tay, J.H. 2017. Membrane fouling control in membrane bioreactors (MBRs) using granular materials. Bioresource technology, 240, 9-24.

57. Jariyaboon, R., Sompong, O., Kongjan, P. 2015. Bio-hydrogen and bio-methane potentials of skim latex serum in batch thermophilic two-stage anaerobic digestion. Bioresource technology, 198, 198-206.

58. Jones, P.R. 2008. Improving fermentative biomass-derived H2-production by engineering microbial metabolism. International Journal of Hydrogen Energy, 33(19), 5122-5130.

59. Judd, S.J. 2017. Membrane technology costs and me. Water research, 122, 1-9.

60. Jung, K.-W., Kim, D.-H., Kim, S.-H., Shin, H.-S. 2011. Bioreactor design for continuous dark fermentative hydrogen production. Bioresource technology, 102(18), 8612-8620.

61. Kapdan, I.K., Kargi, F. 2006. Bio-hydrogen production from waste materials. Enzyme and microbial technology, 38(5), 569-582.

62. Kataoka, N., Miya, A., Kiriyama, K. 1997. Studies on hydrogen production by continuous culture system of hydrogen-producing anaerobic bacteria. Water Science and Technology, 36(6-7), 41-47.

63. Katuri, K.P., Werner, C.M., Jimenez-Sandoval, R.J., Chen, W., Jeon, S., Logan, B.E., Lai, Z., Amy, G.L., Saikaly, P.E. 2014. A novel anaerobic electrochemical membrane bioreactor (AnEMBR) with conductive hollow-fiber membrane for treatment of low-organic strength solutions. Environmental science \& technology, 48(21), 12833-12841.

64. Khan, M., Ngo, H., Guo, W., Liu, Y., Zhou, J., Zhang, J., Liang, S., Ni, B., Zhang, X., Wang, J. 2016. Comparing the value of bioproducts from different stages of anaerobic membrane bioreactors. Bioresource technology, 214, 816-825.

65. Khan, Z., Yusup, S., Ahmad, M.M., Chok, V.S., Uemura, Y., Sabil, K.M. 2010. Review on hydrogen production technologies in Malaysia. International Journal of Engineering \& Technology, 10(2).

66. Kim, J., Kim, K., Ye, H., Lee, E., Shin, C., McCarty, P.L., Bae, J. 2011a. Anaerobic fluidized bed membrane bioreactor for wastewater treatment. Environmental Science and Technology, 45(2), 576-581.

67. Kim, M.-S., Lee, D.-Y., Kim, D.-H. 2011b. Continuous hydrogen production from tofu processing waste using anaerobic mixed microflora under thermophilic conditions. International journal of Hydrogen energy, 36(14), 8712-8718.

68. Kim, M.-S., Na, J.-G., Lee, M.-K., Ryu, H., Chang, Y.-K., Triolo, J.M., Yun, Y.-M., Kim, D.-H. 2016. More value from food waste: lactic acid and biogas recovery. Water research, 96, 208-216.

69. Kim, M., Oh, Y., Yun, Y., Lee, D. 2006. Fermentative hydrogen production from anaerobic bacteria using a membrane bioreactor. Proceedings of the 16th world hydrogen energy conference. Lyon, France.

70. Kim, S.-H., Cheon, H.-C., Lee, C.-Y. 2012. Enhancement of hydrogen production by recycling of methanogenic effluent in two-phase fermentation of food waste. international journal of hydrogen energy, 37(18), 13777-13782.

71. Kleerebezem, R., van Loosdrecht, M.C. 2007. Mixed culture biotechnology for bioenergy production. Current opinion in biotechnology, 18(3), 207-212.

72. Kotay, S.M., Das, D. 2010. Microbial hydrogen production from sewage sludge bioaugmented with a constructed microbial consortium. international journal of hydrogen energy, 35(19), 10653-10659. 
73. Kraemer, J.T., Bagley, D.M. 2007. Improving the yield from fermentative hydrogen production. Biotechnology letters, 29(5), 685-695.

74. Kumar, G., Sivagurunathan, P., Sen, B., Mudhoo, A., Davila-Vazquez, G., Wang, G., Kim, S.-H. 2017. Research and development perspectives of lignocellulose-based biohydrogen production. International Biodeterioration \& Biodegradation, 119, 225-238.

75. La Licata, B., Sagnelli, F., Boulanger, A., Lanzini, A., Leone, P., Zitella, P., Santarelli, M. 2011. Biohydrogen production from organic wastes in a pilot plant reactor and its use in a SOFC. international journal of hydrogen energy, 36(13), 7861-7865.

76. Le-Clech, P., Chen, V., Fane, T.A.G. 2006. Fouling in membrane bioreactors used in wastewater treatment. Journal of Membrane Science, 284(1), 17-53.

77. Lee, D.-Y., Li, Y.-Y., Noike, T. 2009a. Continuous H2 production by anaerobic mixed microflora in membrane bioreactor. Bioresource technology, 100(2), 690-695.

78. Lee, D.-Y., Li, Y.-Y., Noike, T. 2010a. Influence of solids retention time on continuous H2 production using membrane bioreactor. international journal of hydrogen energy, 35(1), 52-60.

79. Lee, D.-Y., Li, Y.-Y., Noike, T., Cha, G.-C. 2008. Behavior of extracellular polymers and bio-fouling during hydrogen fermentation with a membrane bioreactor. Journal of Membrane Science, 322(1), 13-18.

80. Lee, D.-Y., Li, Y.-Y., Oh, Y.-K., Kim, M.-S., Noike, T. 2009b. Effect of iron concentration on continuous $\mathrm{H} 2$ production using membrane bioreactor. international journal of hydrogen energy, 34(3), 1244-1252.

81. Lee, D.-Y., Xu, K.-Q., Kobayashi, T., Li, Y.-Y., Inamori, Y. 2014. Effect of organic loading rate on continuous hydrogen production from food waste in submerged anaerobic membrane bioreactor. international journal of hydrogen energy, 39(30), 16863-16871.

82. Lee, H.-S., Vermaas, W.F., Rittmann, B.E. 2010b. Biological hydrogen production: prospects and challenges. Trends in biotechnology, 28(5), 262-271.

83. Lee, K.-S., Lin, P.-J., Fangchiang, K., Chang, J.-S. 2007. Continuous hydrogen production by anaerobic mixed microflora using a hollow-fiber microfiltration membrane bioreactor. International Journal of Hydrogen Energy, 32(8), 950-957.

84. Lee, K.-S., Tseng, T.-S., Liu, Y.-W., Hsiao, Y.-D. 2012. Enhancing the performance of dark fermentative hydrogen production using a reduced pressure fermentation strategy. International Journal of Hydrogen Energy, 37(20), 15556-15562.

85. Li, C., Fang, H.H. 2007. Fermentative hydrogen production from wastewater and solid wastes by mixed cultures. Critical Reviews in Environmental Science and Technology, 37(1), 1-39.

86. Liao, B.-Q., Kraemer, J.T., Bagley, D.M. 2006. Anaerobic membrane bioreactors: applications and research directions. Critical Reviews in Environmental Science and Technology, 36(6), 489-530.

87. Lin, C.-Y., Lay, C.-H., Sen, B., Chu, C.-Y., Kumar, G., Chen, C.-C., Chang, J.-S. 2012. Fermentative hydrogen production from wastewaters: a review and prognosis. International journal of hydrogen energy, 37(20), 15632-15642.

88. Lin, C., Lay, C. 2005. A nutrient formulation for fermentative hydrogen production using anaerobic sewage sludge microflora. International Journal of Hydrogen Energy, 30(3), 285-292.

89. Lin, H., Peng, W., Zhang, M., Chen, J., Hong, H., Zhang, Y. 2013. A review on anaerobic membrane bioreactors: applications, membrane fouling and future perspectives. Desalination, 314, 169-188.

90. Lin, P.-J., Chang, J.-S., Yang, L.-H., Lin, C.-Y., Wu, S.-Y., Lee, K.-S. 2011. Enhancing the performance of pilot-scale fermentative hydrogen production by proper combinations of HRT and substrate concentration. international journal of hydrogen energy, 36(21), 14289-14294.

91. Liu, W.-T., Chan, O.-C., Fang, H.H. 2002. Microbial community dynamics during start-up of acidogenic anaerobic reactors. Water Research, 36(13), 3203-3210.

92. Maeda, T., Sanchez-Torres, V., Wood, T.K. 2007. Enhanced hydrogen production from glucose by metabolically engineered Escherichia coli. Applied microbiology and biotechnology, 77(4), 879-890.

93. Méndez-Contreras, J.M., López-Escobar, L.A., Martínez-Hernández, S., Cantú-Lozano, D., Ortiz-Ceballos, A.I. 2016. Rheological behavior of physicochemical sludges during methanogenesis suppression and hydrogen production at different organic loading rates. Journal of Environmental Science and Health, Part A, 51(7), 515-522.

94. Meng, F., Zhang, S., Oh, Y., Zhou, Z., Shin, H.-S., Chae, S.-R. 2017. Fouling in membrane bioreactors: an updated review. Water Research, 114, 151-180.

95. Mizuno, O., Ohara, T., Shinya, M., Noike, T. 2000. Characteristics of hydrogen production from bean curd manufacturing waste by anaerobic microflora. Water science and technology, 42(3-4), 345-350. 
96. Mohan, S.V. 2009. Harnessing of biohydrogen from wastewater treatment using mixed fermentative consortia: process evaluation towards optimization. International Journal of Hydrogen Energy, 34(17), 7460-7474.

97. Mohan, S.V., Mohanakrishna, G., Raghavulu, S.V., Sarma, P. 2007. Enhancing biohydrogen production from chemical wastewater treatment in anaerobic sequencing batch biofilm reactor (AnSBBR) by bioaugmenting with selectively enriched kanamycin resistant anaerobic mixed consortia. International Journal of Hydrogen Energy, 32(15), 3284-3292.

98. Nath, K., Das, D. 2006. Amelioration of biohydrogen production by a two-stage fermentation process. Industrial Biotechnology, 2(1), 44-47.

99. Nath, K., Das, D. 2004. Improvement of fermentative hydrogen production: various approaches. Applied microbiology and biotechnology, 65(5), 520-529.

100.Nikolaidis, P., Poullikkas, A. 2017. A comparative overview of hydrogen production processes. Renewable and sustainable energy reviews, 67, 597-611.

101.Niwa, T., Hatamoto, M., Yamashita, T., Noguchi, H., Takase, O., Kekre, K.A., Ang, W.S., Tao, G., Seah, H., Yamaguchi, T. 2016. Demonstration of a full-scale plant using an UASB followed by a ceramic MBR for the reclamation of industrial wastewater. Bioresource technology, 218, 1-8.

102.Noblecourt, A., Christophe, G., Larroche, C., Santa-Catalina, G., Trably, E., Fontanille, P. 2017. High hydrogen production rate in a submerged membrane anaerobic bioreactor. International Journal of Hydrogen Energy, 42(39), 24656-24666.

103.Oh, H.S., Lee, C.H. 2018. Origin and evolution of quorum quenching technology for biofouling control in MBRs for wastewater treatment. Journal of Membrane Science, 554, 331-345.

104.Oh, S.E., Iyer, P., Bruns, M.A., Logan, B.E. 2004. Biological hydrogen production using a membrane bioreactor. Biotechnology and bioengineering, 87(1), 119-127.

105.Ozgun, H., Dereli, R.K., Ersahin, M.E., Kinaci, C., Spanjers, H., van Lier, J.B. 2013. A review of anaerobic membrane bioreactors for municipal wastewater treatment: integration options, limitations and expectations. Separation and Purification Technology, 118, 89-104.

106.Park, J.-H., Anburajan, P., Kumar, G., Park, H.-D., Kim, S.-H. 2017. Biohydrogen production integrated with an external dynamic membrane: A novel approach. International Journal of Hydrogen Energy, 42(45), 27543-27549.

107.Paudel, S., Seong, C.Y., Seo, G.T. 2014. Anaerobic hydrogen fermentation and membrane bioreactor (MBR) for decentralized sanitation and reuse-organic removal and resource recovery. Environmental Engineering Research, 19(4), 387-393.

108.Pearce, G. 2010. SWRO pre-treatment: Cost and sustainability. Filtration \& Separation, 47(2), 36-38.

109.Prescott, L., Harley, J., Klein, D. 2002. Microbiology, 5"'edition, McGraw Hill. Boston Burr Ridge, IL Dubuque, 1A Madison, W1 New York, San Fransisco, Bangkok, Bogota, Caracas, Kualalumpur, Lisbon, London, Madrid, Mexico City, Milan, Montreal, Newdelhi, Santiago, Seoul, Singapore, Sydney, Taipei, Toronto, 1.

110.Ramírez-Morales, J., Tapia-Venegas, E., Nemestóthy, N., Bakonyi, P., Bélafi-Bakó, K., Ruiz-Filippi, G. 2013. Evaluation of two gas membrane modules for fermentative hydrogen separation. international journal of hydrogen energy, 38(32), 14042-14052.

111.Ren, N., Guo, W., Liu, B., Cao, G., Ding, J. 2011. Biological hydrogen production by dark fermentation: challenges and prospects towards scaled-up production. Current opinion in biotechnology, 22(3), 365-370.

112.Saleem, M., Lavagnolo, M.C., Spagni, A. 2018. Biological hydrogen production via dark fermentation by using a side-stream dynamic membrane bioreactor: Effect of substrate concentration. Chemical Engineering Journal, 349, 719-727.

113.Salem, A.H., Brunstermann, R., Mietzel, T., Widmann, R. 2018. Effect of pre-treatment and hydraulic retention time on biohydrogen production from organic wastes. International Journal of Hydrogen Energy, 43(10), 4856-4865.

114.Saqib, S., Rafiq, S., Chawla, M., Saeed, M., Muhammad, N., Khurram, S., Majeed, K., Khan, A.L., Ghauri, M., Jamil, F., Aslam, M. 2018. Facile CO2 Separation in Composite Membranes. Chemical Engineering \& Technology.

115.Seidl, P.R., Goulart, A.K. 2016. Pretreatment processes for lignocellulosic biomass conversion to biofuels and bioproducts. Current Opinion in Green and Sustainable Chemistry, 2, 48-53.

116.Sekoai, P.T., Yoro, K.O., Bodunrin, M.O., Ayeni, A.O., Daramola, M.O. 2018. Integrated system approach to dark fermentative biohydrogen production for enhanced yield, energy efficiency and substrate recovery. Reviews in Environmental Science and Bio/Technology. 
117.Shahid, M.K., Choi, Y.-G. 2018. The comparative study for scale inhibition on surface of RO membranes in wastewater reclamation: $\mathrm{CO} 2$ purging versus three different antiscalants. Journal of Membrane Science, 546, 61-69.

118.Shahid, M.K., Pyo, M., Choi, Y.-G. 2018. The operation of reverse osmosis system with CO 2 as a scale inhibitor: A study on operational behavior and membrane morphology. Desalination, 426, 11-20.

119.Shen, L., Bagley, D.M., Liss, S.N. 2009. Effect of organic loading rate on fermentative hydrogen production from continuous stirred tank and membrane bioreactors. international journal of hydrogen energy, 34(9), 3689-3696.

120.Shen, L., Zhou, Y., Mahendran, B., Bagley, D.M., Liss, S.N. 2010. Membrane fouling in a fermentative hydrogen producing membrane bioreactor at different organic loading rates. Journal of Membrane Science, 360(1-2), 226-233.

121.Shin, C., Bae, J. 2018. Current status of the pilot-scale anaerobic membrane bioreactor treatments of domestic wastewaters: A critical review. Bioresour Technol, 247, 1038-1046.

122.Show, K.-Y., Lee, D.-J., Chang, J.-S. 2011. Bioreactor and process design for biohydrogen production. Bioresource technology, 102(18), 8524-8533.

123.Show, K., Lee, D., Tay, J., Lin, C., Chang, J. 2012. Biohydrogen production: current perspectives and the way forward. International Journal of Hydrogen Energy, 37(20), 15616-15631.

124.Singer, S., Magnusson, L., Hou, D., Lo, J., Maness, P., Ren, Z.J. 2018. Anaerobic membrane gas extraction facilitates thermophilic hydrogen production from Clostridium thermocellum. Environmental Science: Water Research \& Technology.

125.Singh, L., Wahid, Z.A. 2015. Methods for enhancing bio-hydrogen production from biological process: a review. Journal of Industrial and Engineering Chemistry, 21, 70-80.

126. Singhania, R.R., Christophe, G., Perchet, G., Troquet, J., Larroche, C. 2012. Immersed membrane bioreactors: An overview with special emphasis on anaerobic bioprocesses. Bioresource technology, 122, 171-180.

127. Sinha, P., Pandey, A. 2011. An evaluative report and challenges for fermentative biohydrogen production. International Journal of Hydrogen Energy, 36(13), 7460-7478.

128.Sivagurunathan, P., Gopalakrishnan, K., Lin, C.-Y. 2014. Enhancement of fermentative hydrogen production from beverage wastewater via bioaugmentation and statistical optimization. Current Biochemical Engineering, 1(2), 92-98.

129.Sivagurunathan, P., Kumar, G., Bakonyi, P., Kim, S.-H., Kobayashi, T., Xu, K.Q., Lakner, G., Tóth, G., Nemestóthy, N., Bélafi-Bakó, K. 2016. A critical review on issues and overcoming strategies for the enhancement of dark fermentative hydrogen production in continuous systems. international journal of hydrogen energy, 41(6), 3820-3836.

130.Smith, A.L., Stadler, L.B., Cao, L., Love, N.G., Raskin, L., Skerlos, S.J. 2014. Navigating wastewater energy recovery strategies: a life cycle comparison of anaerobic membrane bioreactor and conventional treatment systems with anaerobic digestion. Environmental science \& technology, 48(10), 5972-5981.

131.Smith, A.L., Stadler, L.B., Love, N.G., Skerlos, S.J., Raskin, L. 2012. Perspectives on anaerobic membrane bioreactor treatment of domestic wastewater: a critical review. Bioresource Technology, 122, 149-159.

132.Spagni, A., Casu, S., Farina, R. 2010. Effect of the organic loading rate on biogas composition in continuous fermentative hydrogen production. Journal of Environmental Science and Health Part A, 45(12), 1475-1481.

133. Stuckey, D.C. 2012. Recent developments in anaerobic membrane reactors. Bioresource Technology, 122 , 137-148.

134.Szentgyörgyi, E., Bélafi-Bakó, K. 2010. Anaerobic Membrane Bioreactors. Hungarian Journal of Industry and Chemistry, 38(2), 181-185.

135.Tao, Y., Chen, Y., Wu, Y., He, Y., Zhou, Z. 2007. High hydrogen yield from a two-step process of darkand photo-fermentation of sucrose. International Journal of Hydrogen Energy, 32(2), 200-206.

136. Thauer, R.K., Jungermann, K., Decker, K. 1977. Energy conservation in chemotrophic anaerobic bacteria. Bacteriological reviews, 41(1), 100.

137.Trad, Z., Akimbomi, J., Vial, C., Larroche, C., Taherzadeh, M.J., Fontaine, J.-P. 2015a. Development of a submerged anaerobic membrane bioreactor for concurrent extraction of volatile fatty acids and biohydrogen production. Bioresource technology, 196, 290-300.

138.Trad, Z., Vial, C., Fontaine, J.-P., Larroche, C. 2015b. Modeling of hydrodynamics and mixing in a submerged membrane bioreactor. Chemical Engineering Journal, 282, 77-90. 
139.Turner, J., Sverdrup, G., Mann, M.K., Maness, P.C., Kroposki, B., Ghirardi, M., Evans, R.J., Blake, D. 2008. Renewable hydrogen production. International journal of energy research, 32(5), 379-407.

140.Wang, A., Sun, D., Cao, G., Wang, H., Ren, N., Wu, W.-M., Logan, B.E. 2011. Integrated hydrogen production process from cellulose by combining dark fermentation, microbial fuel cells, and a microbial electrolysis cell. Bioresource Technology, 102(5), 4137-4143.

141.Wang, J., Wan, W. 2009. Factors influencing fermentative hydrogen production: a review. International journal of hydrogen energy, 34(2), 799-811.

142.Wang, Z., Ma, J., Tang, C.Y., Kimura, K., Wang, Q., Han, X. 2014. Membrane cleaning in membrane bioreactors: a review. Journal of Membrane Science, 468, 276-307.

143.Werner, C.M., Katuri, K.P., Hari, A.R., Chen, W., Lai, Z., Logan, B.E., Amy, G.L., Saikaly, P.E. 2016. Graphene-coated hollow fiber membrane as the cathode in anaerobic electrochemical membrane bioreactors-Effect of configuration and applied voltage on performance and membrane fouling. Environmental science \& technology, 50(8), 4439-4447.

144.Winter, C.-J. 2009. Hydrogen energy - abundant, efficient, clean: a debate over the energy-system-ofchange. International Journal of hydrogen energy, 34(14), S1-S52.

145.Wong, Y.M., Wu, T.Y., Juan, J.C. 2014. A review of sustainable hydrogen production using seed sludge via dark fermentation. Renewable and Sustainable Energy Reviews, 34, 471-482.

146. Yang, Y., Li, J. 2018. Simulation of photobioreaction for hydrogen production in membrane bioreactor with an optical fiber. Applied Physics A, 124(5), 372.

147.Yasin, M., Jeong, Y., Park, S., Jeong, J., Lee, E.Y., Lovitt, R.W., Kim, B.H., Lee, J., Chang, I.S. 2015. Microbial synthesis gas utilization and ways to resolve kinetic and mass-transfer limitations. Bioresource Technology, 177, 361-374.

148. Yasin, M., Park, S., Jeong, Y., Lee, E.Y., Lee, J., Chang, I.S. 2014. Effect of internal pressure and gas/liquid interface area on the CO mass transfer coefficient using hollow fibre membranes as a high mass transfer gas diffusing system for microbial syngas fermentation. Bioresource technology, 169, 637-643.

149. Yoshida, A., Nishimura, T., Kawaguchi, H., Inui, M., Yukawa, H. 2006. Enhanced hydrogen production from glucose using ldh-and frd-inactivated Escherichia coli strains. Applied microbiology and biotechnology, 73(1), 67-72. 